\title{
Homogenization and Assessment of Observed Near-Surface Wind Speed Trends across Sweden, 1956-2013
}

\author{
LORENZO MiNOLA \\ Regional Climate Group, Department of Earth Sciences, University of Gothenburg, Gothenburg, Sweden \\ CESAR AZOrin-Molina \\ Departamento de Procesos Geoambientales y Cambio Global, Instituto Pirenaico de Ecología, Consejo Superior \\ de Investigaciones Científicas, Zaragoza, Spain \\ DELIANG CHEN \\ Regional Climate Group, Department of Earth Sciences, University of Gothenburg, Gothenburg, Sweden
}

(Manuscript received 18 August 2015, in final form 13 July 2016)

\begin{abstract}
Multidecadal variability of observed near-surface wind speed from 24 stations across Sweden has been analyzed for 1956-2013, with a focus on 1979-2008 (incorporating an additional 9 stations) for comparison with previous studies. Wind speed data have been subjected to a robust data processing protocol, consisting of quality control, reconstruction, and homogenization, by using geostrophic wind speed series as reference. The homogenized dataset displays a significant (at $p<0.05)$ downward trend for 1956-2013 $\left(-0.06 \mathrm{~m} \mathrm{~s}^{-1} \mathrm{decade}^{-1}\right)$ and an even larger decreasing trend for 1979-2008 $\left(-0.14 \mathrm{~m} \mathrm{~s}^{-1}\right.$ decade $\left.^{-1}\right)$. However, differences have been observed seasonally, with significant decreasing values in spring, summer, and autumn and a small downward trend in winter for 1956-2013. Most interestingly, a nonsignificant wind speed increase has been detected in winter for 1979-2008, which contrasts with the marked "stilling" reported for this season in much of midlatitude regions. The decreasing rate in wind speed is larger for coastal stations and in the southern part of Sweden. Decreasing trends were found at $91.7 \%$ of the stations during summer, whereas $58.3 \%$ of the stations displayed decreasing trends in winter. On the contrary, increasing trends occurred in $41.7 \%$ of the stations for winter and in only $8.3 \%$ for summer. The possible impact of the North Atlantic Oscillation (NAO) index has also been investigated, showing evidence that the small increasing trend in winter for 1979-2008 is hypothetically associated with the positive tendency of the NAO index during the last decades. These results reveal the influence of large-scale atmospheric circulation on wind speed variability across Sweden.
\end{abstract}

\section{Introduction}

During the last two decades, several studies have investigated near-surface wind speed changes in the United States (Klink 1999; Pryor et al. 2007, 2009), Canada (Wan et al. 2010), China (Xu et al. 2006; Fu et al.

Supplemental information related to this paper is available at the Journals Online website: http://dx.doi.org/10.1175/ JCLI-D-15-0636.s1.

Corresponding author address: Deliang Chen, Department of Earth Sciences, University of Gothenburg, Box 460, 40530 Gothenburg, Sweden.

E-mail: deliang@gvc.gu.se
2011; Guo et al. 2011), Australia (McVicar et al. 2008), Europe (Brázdil et al. 2009; Cusack 2013; AzorinMolina et al. 2014, 2016), and many other regions across the globe. The term wind "stilling" was introduced for the first time by Roderick et al. (2007) to refer to the local slowdown of the terrestrial near-surface wind speed over Australia. Decrease in near-surface winds has been reported over land in most northern midlatitude regions during the last decades (McVicar et al. 2012). However, ocean wind speed measurements based on altimeters and ship anemometer readings have revealed an opposite increasing trend in wind speed over large parts of oceans (Gower 2002; Thomas et al. 2008; Young et al. 2011). In addition, seasonal and monthly differences in the sign and magnitude of the reported 
wind speed trends have been detected for some regions (Klink 1999; Azorin-Molina et al. 2014, 2016).

So far the wind speed investigations have mainly focused on midlatitude areas where the majority of nearsurface wind speed measurements are available (McVicar et al. 2012), which contrasts with the fewer number of studies for high latitudes in the Northern Hemisphere such as Canada (Wan et al. 2010), Alaska (Lynch et al. 2004; Hartmann and Wendler 2005), and Russia (Gruza et al. 2008). Indeed, there have been no such studies dealing with linear trend and multidecadal variability for such high latitudes in Europe. Therefore, it is of great scientific interest in the framework of the widespread terrestrial stilling debate to conduct for the first time an assessment of linear trend and multidecadal variability of observed near-surface wind speed across Sweden (lying between latitudes $55^{\circ}$ and $70^{\circ} \mathrm{N}$ ). This is because (i) no research on this topic has been conducted before for Sweden with respect to the recent widespread stilling in terrestrial near-surface wind, (ii) only very little evidence on the behavior of wind speed trends is available for such high latitudes like the Scandinavian Peninsula, and (iii) studying wind speed variability at high latitudes would help to reveal any latitudinal dependence of trends (e.g., hypothetically attributed to changes in large-scale atmospheric circulation) by comparison with previous results at mid- and low latitudes.

Winds over Scandinavia are generally dominated by those from westerly and southwesterly directions, driven by the interannual fluctuations in the strength of the Icelandic low and the Azores high, measured by the North Atlantic Oscillation (NAO) index (Jönsson and Fortuniak 1995; Chen 2000; Hanssen-Bauer and Førland 2000). Surface winds across Sweden are therefore controlled by the cyclonic and anticyclonic circulations over Europe (Chen 2000; Achberger et al. 2006), in particular cyclones developed over the arctic and polar fronts (Martyn 1992). In the eastern region of the north-southaligned Scandinavian mountain range (herein the Scandes), the numerous valleys in the northwest-southeast direction partly force winds to follow the valley orientation (Achberger et al. 2006). The absence of mountain sheltering in the west of the southern region exposes the area to westerlies (i.e., winds from the west or southwest directions; Jönsson and Fortuniak 1995). Local wind systems (i.e., sea breezes and local winds) can develop from the longextended coastline, the numerous lakes, or the Scandes topography, but the strong regional winds overcome these local winds for much of the year (Borne et al. 1998; Achberger et al. 2006).

The major goal of this research is to analyze trend and multidecadal variability of wind speed across Sweden to assess possible changes to climate variability in homogenized near-surface wind speed data. In particular, this study aims to (i) obtain high-quality near-surface wind speed series for Sweden by applying a robust data processing protocol, (ii) assess the spatiotemporal variation of linear trend and multidecadal variability of nearsurface wind speed across Sweden for the 58-yr period of 1956-2013 (with a focus on the 1979-2008 subperiod for comparison purposes), and, as a secondary objective, (iii) investigate the possible influence of the NAO as a largescale atmospheric circulation pattern on the observed wind speed trends. To meet these research objectives, observed wind speed series have been subjected to a robust data processing protocol using geostrophic wind speed series as reference (sections 2 and 3). By a trend data analysis (section 4), the spatiotemporal variability of near-surface wind speed across Sweden has been assessed and the influence of the NAO index on the observed trends has been investigated (section 5). At the end, a summary and discussion are presented (section 6).

\section{Datasets}

\section{a. Wind speed data}

Wind speed data used in this study are provided by the Swedish Meteorological and Hydrological Institute (SMHI). All the meteorological observations are available online (downloaded from http://opendata-catalog. smhi.se/explore/). Wind speed has been measured with either cup anemometers or a Thies ultrasonic anemometer 2D (Fig. S1 in the supplementary material). Before 1995, wind speed was measured with the Söderlund mechanical cup anemometers located on lighthouses or at airport meteorological stations (Achberger et al. 2006), and measurements were mostly recorded every $3 \mathrm{~h}$. Wind speed observations were concentrated along the coastline and in southern Sweden, with a sparse measuring station density in northern inland areas of Sweden. In 1996 SMHI started to install about 120 automatic weather stations (AWS) across the country, being equipped with the Thies ultrasonic anemometer 2D placed at the standard height of $10 \mathrm{~m}$ above the ground (Wern and Bärring 2009). Measurements at AWS have been made every hour. The measured wind speed is the averaged value over $10 \mathrm{~min}$ and is reported in meters per second.

Alexandersson (2006) reported that across Sweden most stations (not specified which ones) measured near-surface wind speed at the standard height of $10 \mathrm{~m}$ during 1961-2004, with the exception of some coastal stations where anemometers were located at the top of lighthouses on hills and rocky islands. For those coastline monitoring stations the measuring height in practice ended up to be higher 

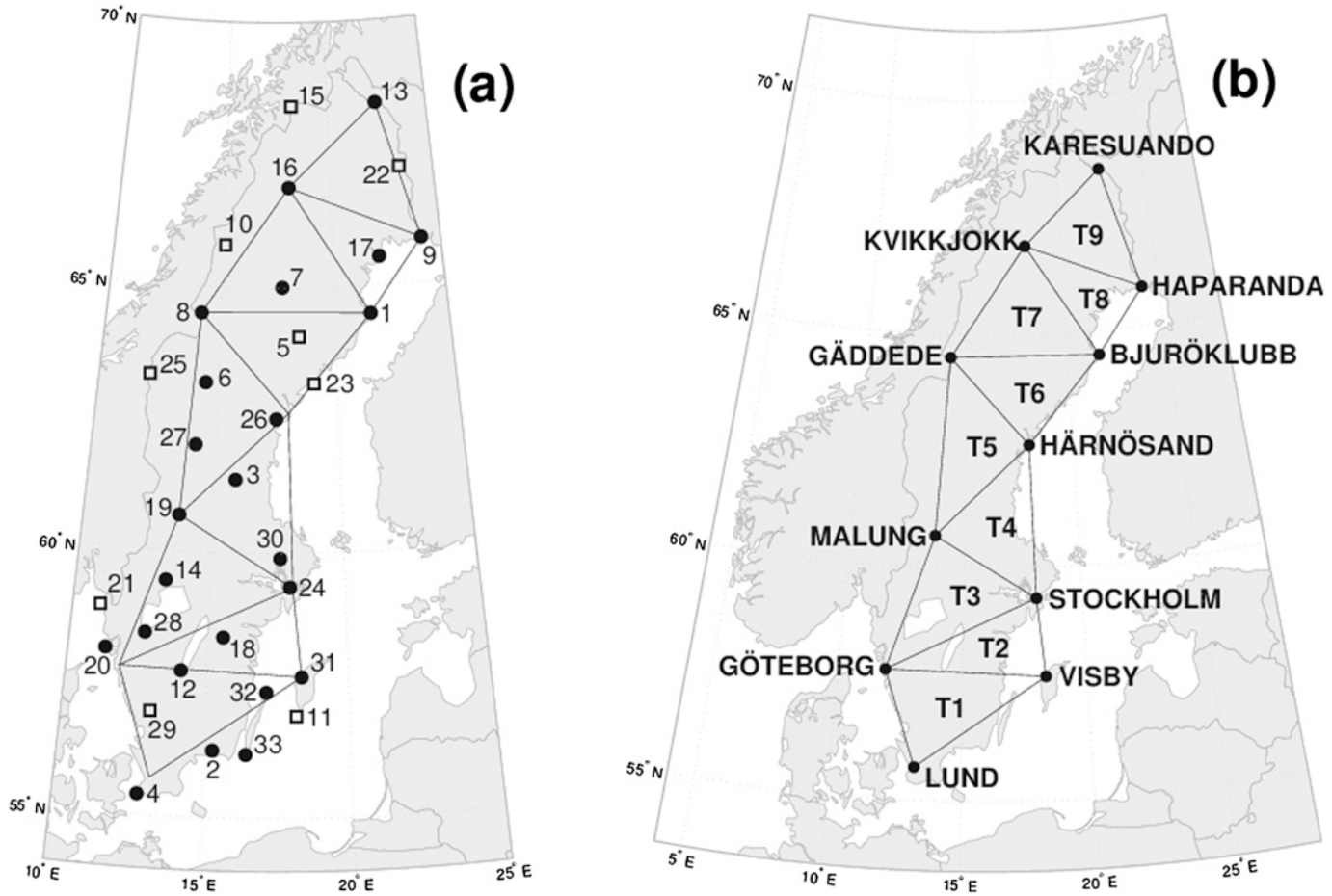

FIG. 1. (a) Location of the 33 weather stations used in this study (for details of the stations see Table S1) and the nine pressure triangles defined to calculate geowind series. While the 24 monitoring stations analyzed for 1956-2013 are shown as black filled circles, the 9 stations added for 1979-2008 are shown as unfilled squares. (b) Location of the nine pressure triangles (labeled T1-T9) to calculate geowind series; the names of the stations with air pressure data at the vertices are reported.

than $10 \mathrm{~m}$. Consequently, there are some uncertainties with respect to the measuring height of several coastal stations, which cannot be resolved with the available information from SMHI. Only after 1996, when SMHI installed new AWS all across the country, did the wind speed measuring network use identical anemometers at the same standard measuring height of $10 \mathrm{~m}$ above the ground (Wern and Bärring 2009).

Among the existing 541 weather stations with wind speed data available, only 24 of them (see Table S1 in the supplementary material) have been chosen as they cover the entire 58-yr period of 1956-2013. Those observed data series have been selected because they offer a good compromise between the following selection criteria: (i) series covering the longest possible multidecadal time period (at least around $60 \mathrm{yr}$ ), (ii) series with the fewest and the shortest possible periods with missing values (no more than 60 missing months), (iii) series that have undergone the fewest relocations (no more than 5 relocations reported by the available metadata), and (iv) series from meteorological stations that cover Sweden reasonably evenly (Fig. 1a). Although measurements should have been recorded every $3 \mathrm{~h}$ (prior to 1995) or every hour (since 1996) according to the metadata given by the
SMHI, wind speed observations are only available every $6 \mathrm{~h}$ in the early times for some stations. Therefore, in this study mean monthly near-surface wind speed series have been calculated for each of the 24 meteorological stations considering only the observations at 0000, 0600, 1200, and 1800 UTC (i.e., the synoptic times available for all the 24 series during the whole 58-yr period). Following Wan et al. (2010) and Azorin-Molina et al. (2014), monthly means have been calculated for months with at least 26 days of observations, after excluding days with fewer than three observations. Otherwise the whole month has been set as missing.

To adopt the results of Vautard et al. (2010) and Azorin-Molina et al. (2014) as reference for comparison purposes, the 30-yr subperiod of 1979-2008 has also been investigated. Over this subperiod, the 24 stations chosen for the 58-yr period of 1956-2013 have been used, and 9 additional weather stations have also been included, making a total of 33 wind speed series for 1979-2008 (Table S1). The nine new data series have been chosen since (i) they cover the 30 -yr subperiod of 1979-2008, (ii) they have the fewest and the shortest possible periods with missing values (no more than 36 
missing months), (iii) they have undergone the fewest relocations (no more than 60 months), and (iv) they nicely improve the spatial representation across Sweden, in addition to the already selected 24 meteorological stations for 1956-2013 (Fig. 1a). The mean monthly and missing values for 1979-2008 are set by applying the same criteria described above for 1956-2013. All these 33 selected time series have been subjected to the homogenization protocol described in section 3 .

\section{b. Geostrophic wind speed data}

In this study the geostrophic wind speed data (geowind) have been used as reference series for adjusting significant discontinuities in the observed wind speed series. The geowind series needed for this study have been provided by the previous works of Wern and Bärring $(2009,2011)$. The calculation of a geowind series is based on air pressure observations from three weather station sites forming a triangle over the study area, together with the air temperature and latitude information. The geowind series is considered as the regional mean of the central part of the triangle. Wern and Bärring (2011) identified nine air pressure triangles across Sweden (Fig. 1b). Geowind speed values in the data series provided by Wern and Bärring (2011) are available for the 58-yr period of 1956-2013 at three synoptic times (i.e., at 0600, 1200, and 1800 UTC, with the 0000 UTC missing). Monthly mean geowind series have been calculated for each of the nine pressure triangles for the 58-yr period of 1956-2013 and represent a first-order proxy of real wind speed showing the same climate signal of the candidate station series (Wan et al. 2010). Furthermore, pressure observations from which geowind series are created are more homogeneous than near-surface wind measurements because they are not disturbed by surrounding or instrument changes such as anemometer measurements (Wern and Bärring 2011). For more information about the procedure to create the geowind speed series for Sweden refer to SMHI (http://www. smhi.se/klimatdata/meteorologi/vind/klimatindikatorgeostrofisk-vind-1.3971 and http://www.smhi.se/klimatdata/ meteorologi/vind/klimatindikator-geostrofisk-vind-se-ochladda-ner) and the previous studies of Wern and Bärring (2009, 2011).

Wan et al. (2010) explained how to match the observed wind speed series from a weather station with the corresponding geowind speed series. In general, the geowind series from the triangle that covers the weather station is used as reference series. However, for those stations that are not in any of the nine triangles, including those that were used to build the pressure triangles (located right on a boundary between triangles), the geowind series that has the highest
Pearson's correlation coefficient against the observed series has been used.

\section{c. NAO index}

The NAO is considered the main mode for winter climate variability over extended regions of the Northern Hemisphere, such as Europe (Wallace and Gutzler 1981; Hanssen-Bauer and Førland 2000) and as one of the most influential atmospheric teleconnection patterns for the climate variability across Sweden (Hurrell and van Loon 1997; Chen and Hellström 1999; Linderholm et al. 2011); therefore, its possible influence on near-surface wind speed trends has been investigated in this study. The NAO index series has been obtained from the Climatic Research Unit, University of East Anglia (available online at http://www.cru.uea.ac.uk/ $\mathrm{cru} / \mathrm{data} / \mathrm{nao} /$ ), and calculated using station-derived pressure series. The definition of NAO index adopted here is the one defined by Jones et al. (1997); that is, the NAO index is the normalized pressure difference between Gibraltar and southwestern Iceland (e.g., Reykjavik). The Climatic Research Unit provides NAO index values until December 2000. To complete the NAO index series for the whole 1956-2013 period, the NAO index updates by Tim Osborn from January 2001 to December 2013 have been used (available online at http://www.cru.uea.ac.uk/ timo/datapages/ naoi.htm).

\section{Data processing of wind speed series}

Multidecadal wind speed time series can be affected by different sources of inhomogeneities (Aguilar et al. 2003; Pryor et al. 2009; Wan et al. 2010; Azorin-Molina et al. 2014), with station relocations and/or anemometer height changes being the main causes of discontinuities (Wan et al. 2010). To create robust multidecadal climate series, we have followed a multistep approach (El Kenawy et al. 2013) consisting of (i) quality control (QC), (ii) reconstruction, and (iii) homogenization.

\section{a. Quality control}

SMHI (L. Hallingfors 2014, personal communication) has run some QC to flag suspicious and erroneous values. Before the 1980s, the QCs were performed manually, whereas after that time some QC algorithms were automatically applied. Rissanen et al. (2000) analyzed the QC procedures (mainly consisting of range and consistency checks) that wind speed observations undergo in the latest AWS. Detailed QC procedures and criteria to identify suspicious hourly wind speed values by the recent algorithms in AWS are reported in Table S2 of the supplementary material. No further QC checks 
(a)

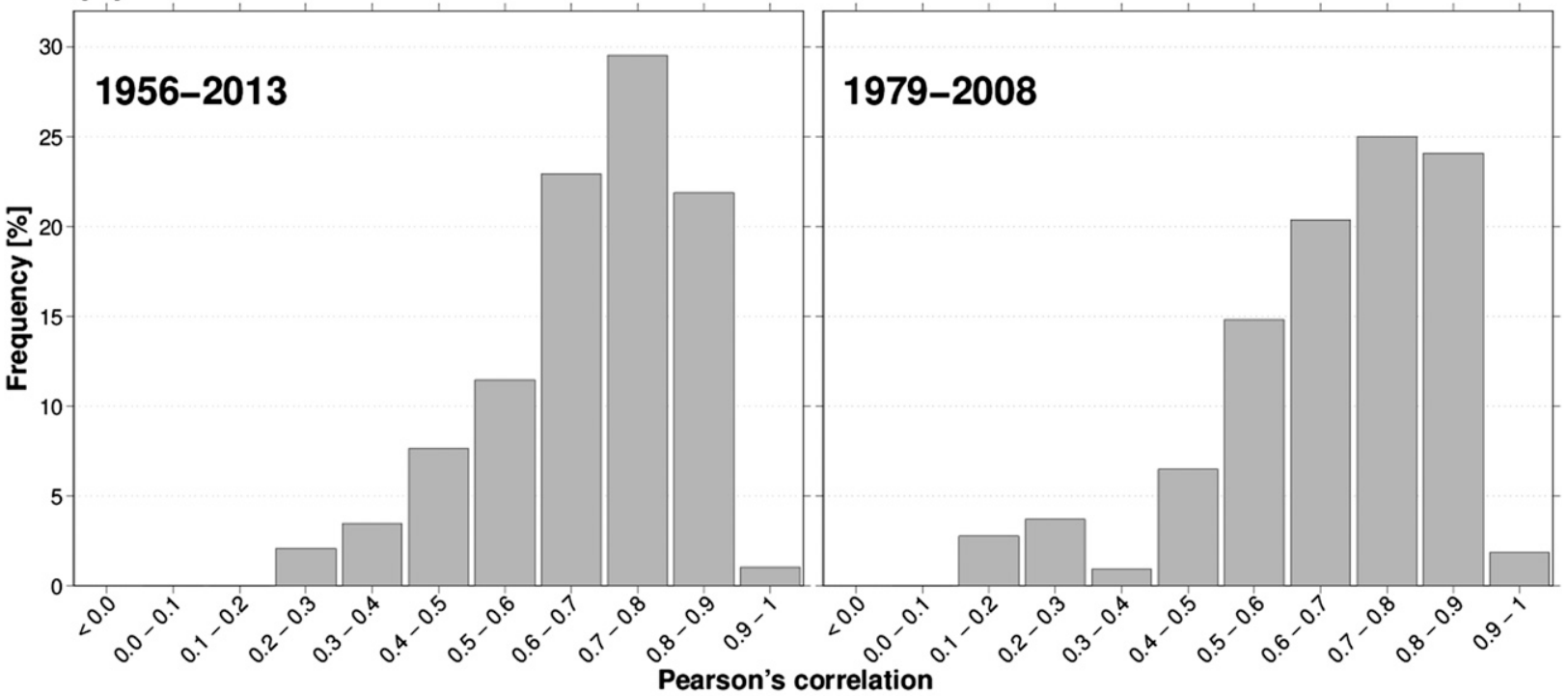

(b)
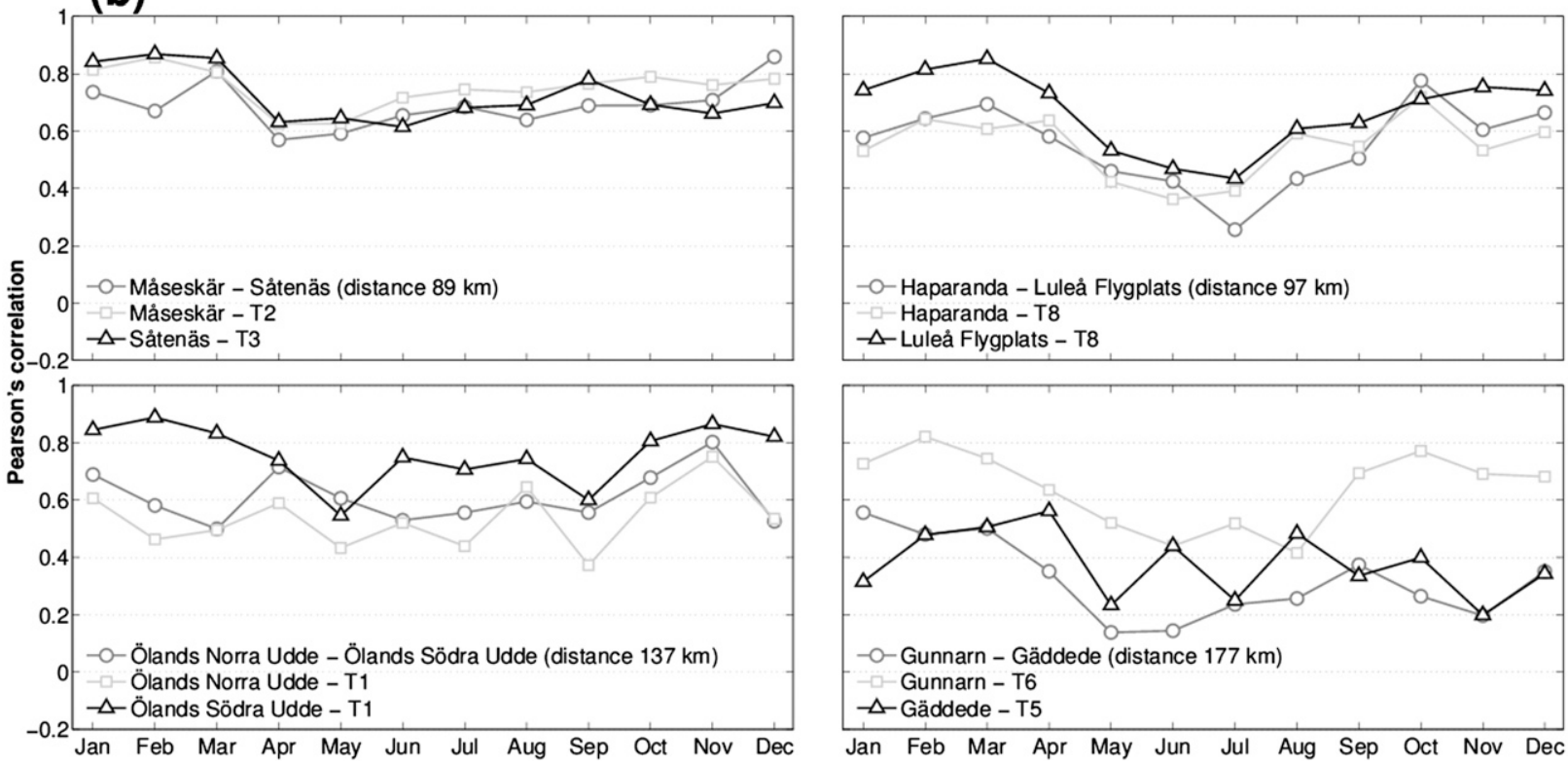

FIG. 2. Statistical relationship between observed wind speed and geowind series. (a) Relative frequency histogram of the Pearson's correlation coefficients between the 24 (1956-2013) and 33 (1979-2008) observed wind speed series and the corresponding geowind series. (b) Monthly Pearson's correlation coefficients between the observed wind speed series at four locations (Måseskär, Haparanda, Ölands Norra Udde, and Gunnarn) and nearby stations at short (Såtenäs), medium (Luleå Flygplats and Ölands Södra Udde), and long distances (Gäddede) (dark gray line) and the geowind series (light gray line). Monthly Pearson's correlation coefficients between the nearby stations and the corresponding geowind series are also shown (black line).

have been applied in this study as QC procedures followed by SMHI have been considered satisfactory.

\section{b. Reconstruction}

To get a complete wind speed series, the reconstruction of fragmented data series must be compiled. The reconstruction task involves concatenation of old and new monitoring stations due to relocation or replacement by AWS. This occurred in 16 out of the 33 weather stations. The dates of replacement between old and new stations (i.e., when data series were joined) were registered and considered during the homogenization procedure described below since fragmentations may introduce noise to estimate multidecadal climate changes (El Kenawy et al. 2013). 

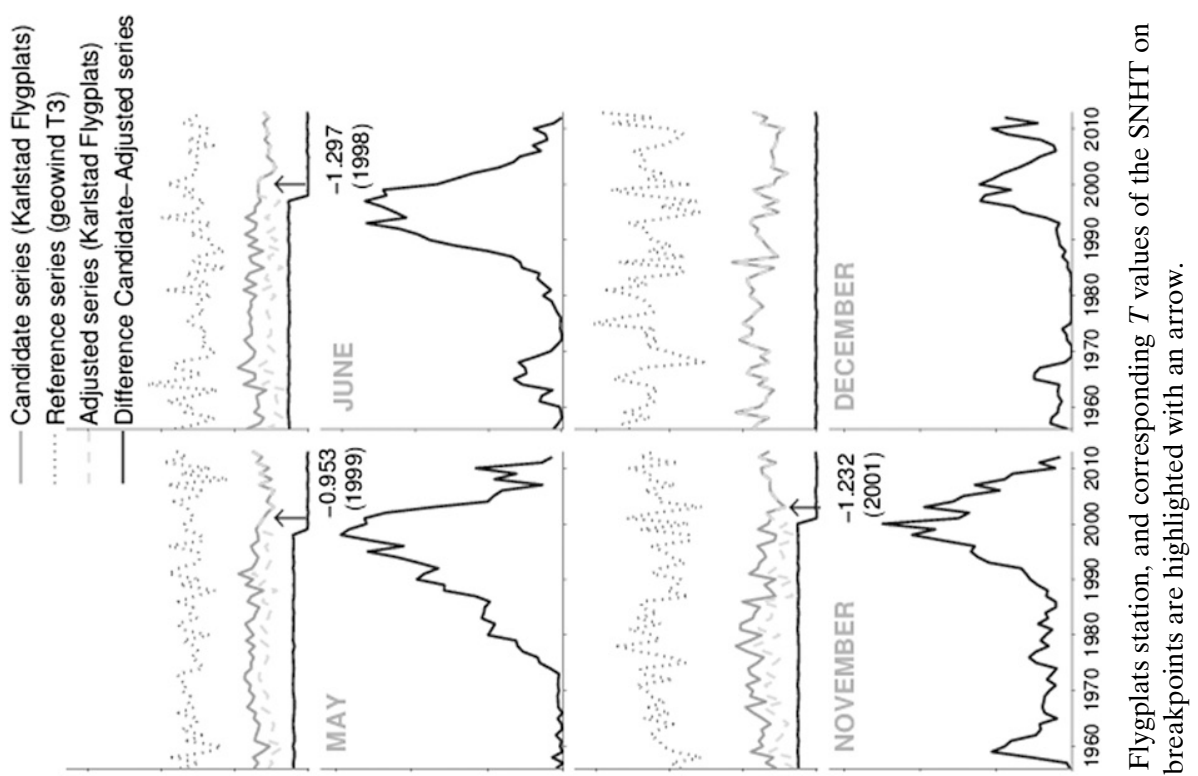

每

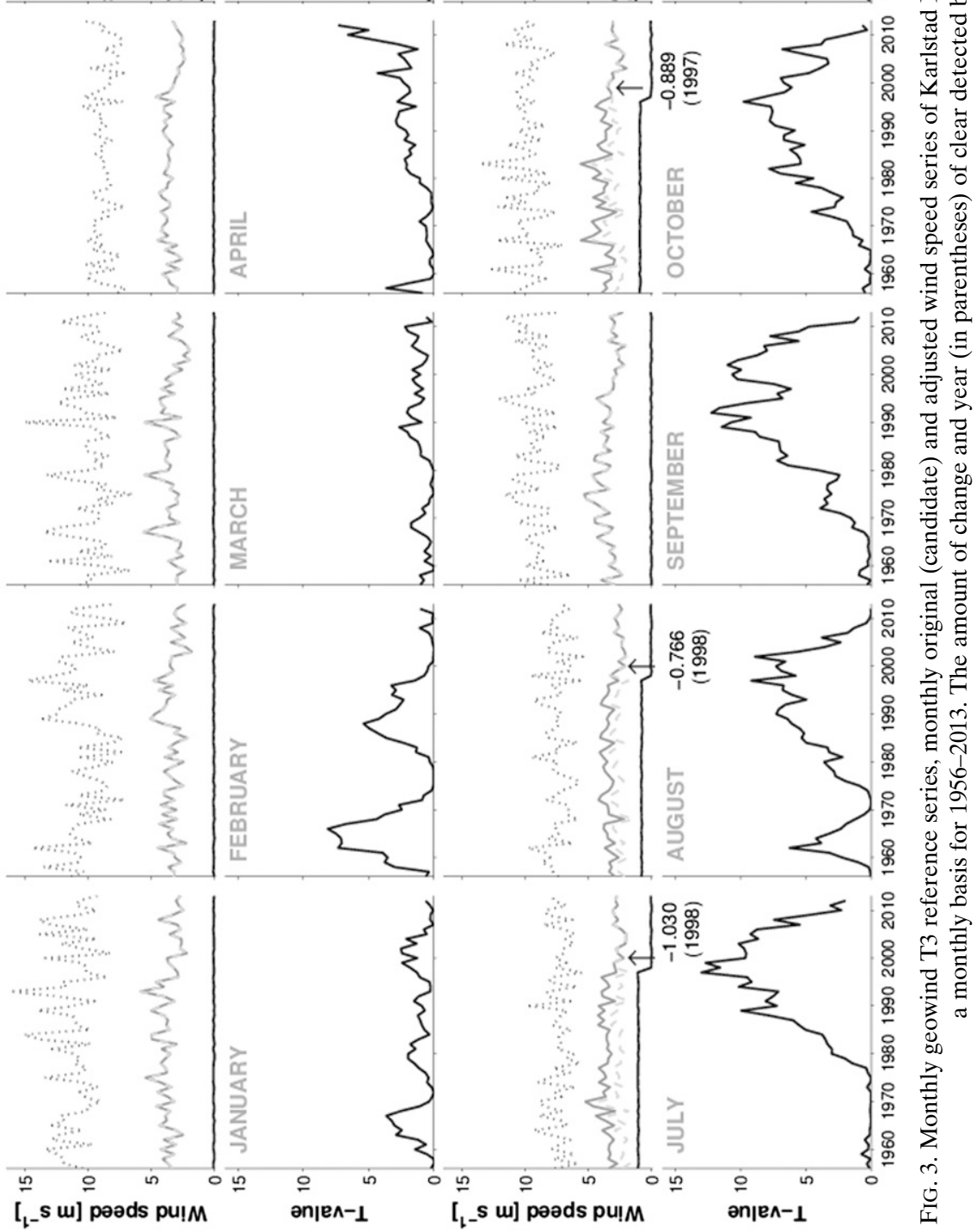


TABLE 1. Annual and seasonal wind speed trends $\left(\mathrm{m} \mathrm{s}^{-1}\right.$ decade $\left.^{-1}\right)$ averaged over all the stations for 1956-2013 (24 stations) and 1979-2008 (33 stations). Statistically significant trends are shown in boldface for $p<0.05$ and in italic for $p<0.10$.

\begin{tabular}{lcc}
\hline \multicolumn{1}{c}{ Period } & $1956-2013$ & $1979-2008$ \\
\hline Annual & $\mathbf{- 0 . 0 6}$ & $\mathbf{- 0 . 1 4}$ \\
Winter (DJF) & -0.04 & -0.01 \\
Spring (MAM) & $\mathbf{- 0 . 0 6}$ & $\mathbf{- 0 . 1 5}$ \\
Summer (JJA) & $\mathbf{- 0 . 1 0}$ & $\mathbf{- 0 . 1 1}$ \\
Autumn (SON) & $\mathbf{- 0 . 0 7}$ & $\mathbf{- 0 . 2 6}$ \\
\hline
\end{tabular}

\section{c. Homogenization}

The homogenization procedure was based on monthly mean series of geowind speed as reference series following Wan et al. (2010). Geowind series can be considered suitable reference series because (i) winds in Sweden are controlled much more by large-scale synoptic systems (i.e., pressure gradient forces) than by local thermal gradients (Jönsson and Fortuniak 1995; Borne et al. 1998; Achberger et al. 2006) and (ii) complex topography (except for the western part of the country) is not a feature of the surface roughness in Sweden (Achberger et al. 2006). Figure 2a illustrates the high Pearson's correlation coefficients found between observed wind speed series and the corresponding geowinds. For both 1956-2013 and 1979-2008 periods the most frequent Pearson's correlation range corresponds to 0.7-0.8. Moreover, Fig. 2b shows the monthly Pearson's correlation coefficients between the wind speed series measured at four locations (i.e., Måseskär, Haparanda, Ölands Norra Udde, and Gunnarn) and their corresponding geowind reference series and nearby stations located at short, medium, and long distances. It also illustrates the Pearson's correlation coefficients between the neighboring stations and their corresponding geowind series. In general Pearson's correlation coefficients show a closer positive relationship for the geowind series than that for the observed nearby series for the majority of months in each of the paired locations especially at long distances. Therefore, it can be assumed that geowind series are better reference series compared to other possible ones such as those from neighboring stations.

The homogeneity of the selected 33 monthly wind speed series has been tested by applying the Alexandersson's standard normal homogeneity test (SNHT; Alexandersson 1986). In particular the SNHT has been used for detecting inhomogeneities by using the AnClim software (http://www.climahom.eu/softwaresolution/anclim) developed by Stepanek (2004). The SNHT has been applied to all the 33 candidate stations on a monthly basis using the respective geowind series as reference series for each station. In applying the SNHT three general rules have been taken into account: 1) AnClim detects all the possible inhomogeneities at a statistically significance level of $5 \%$-these detected breakpoints have only been homogenized when metadata is available and, in case of no metadata available, when they occur for different months around the same year; 2) wind speed series have been adjusted by applying the amount of change before the detected inhomogeneity, assuming that the most recent wind speed measurements are more reliable; and 3) inhomogeneities detected within the first and last $5 \mathrm{yr}$ of the wind speed series have been rejected as the low number of years can affect the detection of breakpoints by lowering the stability of average values (Göktürk et al. 2008). The SNHT has been applied several times (i.e., iteration of the homogeneity test) until dominant and less prominent inhomogeneities have been corrected. An example of the homogenization protocol can be found in the wind speed series of Karlstad Flygplats (Fig. 3). Available metadata informs that the station was subjected to relocation (both change of location and elevation) between September and October 1997. This artificial shift has been detected and homogenized by the SNHT showing significant breakpoints for 6 out of 12 monthly series, in particular October 1997, June 1998, July 1998, August 1998, May 1999, and November 2001. Five other significant breaks have been identified but not adjusted (August 1963, June 1969, January 1980, February 1989, and September 1993).

To summarize, significant breakpoints have been detected and corrected in 55 out of the 288 monthly series tested from the 24 meteorological stations for 1956-2013 (i.e., in $19.1 \%$ of the total number of monthly series) and in 17 out of the 108 monthly series analyzed from the 9 meteorological stations introduced for 1979-2008 (i.e., in $15.7 \%$ of the total number of monthly series). The applied homogenization protocol is summarized in Table S3 of the supplementary material where all the available metadata and detected and adjusted breakpoints are reported. Figure S2 in the supplementary material shows the distribution of detected and adjusted breakpoints. After applying the homogenization procedure by adjusting clear breakpoints, missing values (with maximum 54 months at Jönköping Gamla Flygplat) have been filled in the new homogeneous wind speed series by using the geowind monthly series. In this way completeness of the observed wind speed series has been achieved, which enables reliable assessment of linear trend and multidecadal variability. Although there is no guarantee that all possible inhomogeneities 

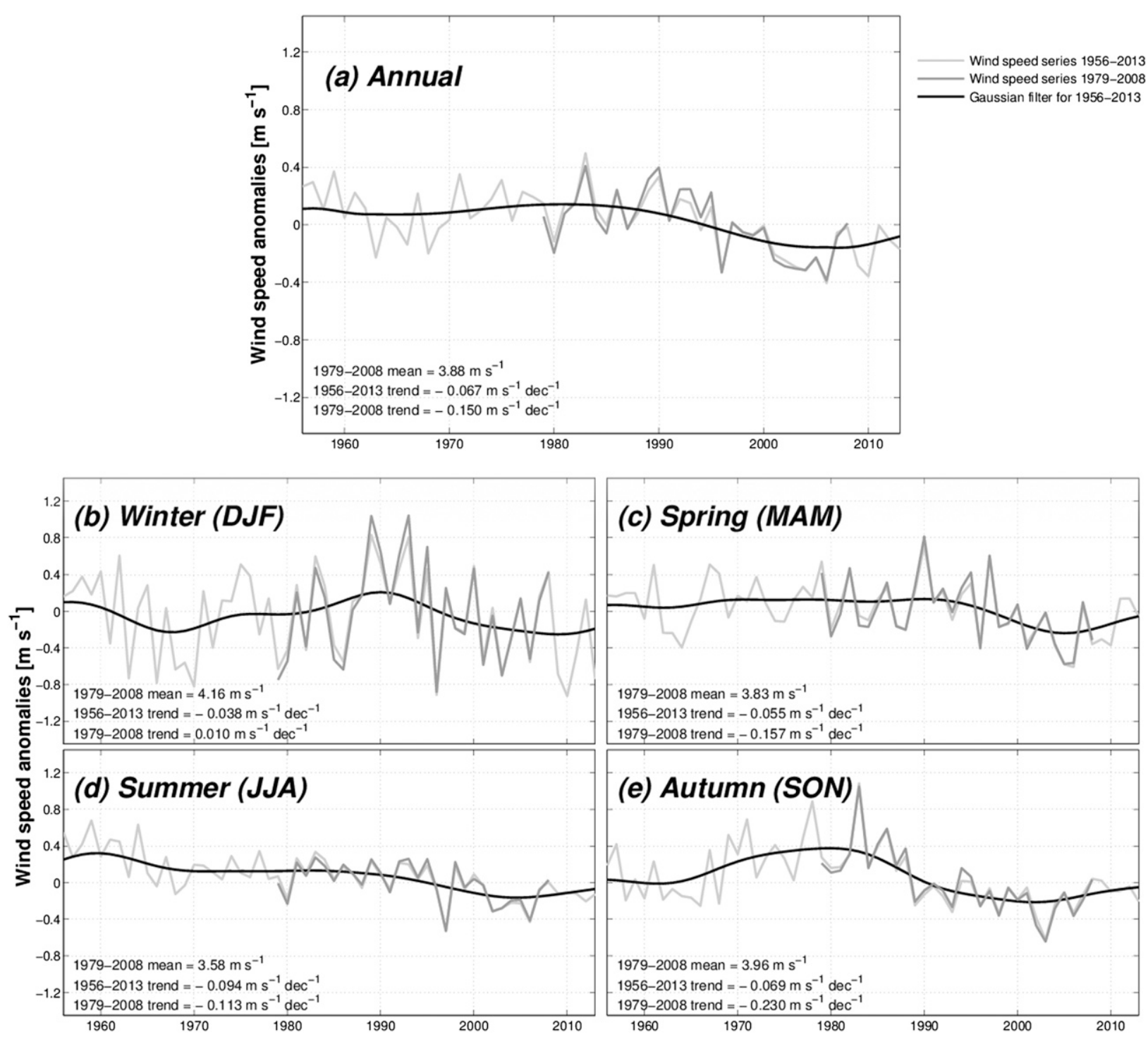

FIG. 4. Series of mean annual and seasonal wind speed anomalies $\left(\mathrm{m} \mathrm{s}^{-1}\right)$ for Sweden from 1956 to 2013 (light gray line) and from 1979 to 2008 (dark gray line). The Gaussian low-pass filter (with $\sigma=4$ ) for 1956-2013 is shown with a black line to illustrate the multidecadal variability. The series are expressed as anomalies from the 1979-2008 mean.

have been detected and adjusted with the methods used in this study, the homogenized wind speed series is considered most reliable given the information available and thus used for assessing near-surface wind speed variability for 24 (1956-2013) and 33 (1979-2008) stations across Sweden; this last subperiod is used for comparison purposes with the results achieved by Vautard et al. (2010) and Azorin-Molina et al. (2014).

\section{Trend analysis}

Linear trends in the homogenized wind speed series have been estimated by applying a linear fitting between the wind speed anomaly series and series of time. Multidecadal variability was identified with help of a lowpass Gaussian filter (with $\sigma=4$ ). The anomalies were obtained for each wind speed series as deviation from the 1979-2008 mean, which represents the common period for all the 24 (and 33) homogenized series. Mean anomaly series for Sweden have been constructed at annual, seasonal, and monthly bases by averaging wind speed anomalies from the 24 stations for 1956-2013 and from the 33 stations for 1979-2008. Wind speed series have been expressed as anomalies to minimize the issue of windy series dominating the regional wind speed series (Azorin-Molina et al. 2014). 
The sign and the magnitude of the wind speed trend are represented by the positive or negative slope of the regression analysis and are expressed in meters per second per decade. In particular the slope of the linear trend is estimated with the nonparametric Sen's method (Gilbert 1987). The statistical significance of the linear trends has been estimated by using the modified Mann-Kendall trend test for autocorrelated data designed by Hamed and Rao (1998). This test has been applied instead of the conventional parametric $\tau_{b}$ Mann-Kendall's correlation coefficient (Kendall and Gibbons 1990) to take into account the high autocorrelation of the wind speed anomalies series. In fact, von Storch (1995) showed that significant autocorrelation in the candidate series could increase the probability that the $\tau_{b}$ test detects a significant trend even if it is absent and vice versa. The 1-month lag autocorrelation coefficient has been calculated for all the wind speed series, and statistically significant (at $p<0.05)$ serial correlation at lag 1 has been detected for a large number of the wind speed anomalies series. Instead of the prewhitening procedure to remove any significant autocorrelation on the wind speed series as suggested by von Storch (1995), the modified MannKendall trend test has then been applied to take into account the effect of autocorrelation by changing the variance of the Mann-Kendall $S$ statistic (Hamed and Rao 1998; Karmeshu 2012). On the contrary, because no statistically significant lag-1 autocorrelation has been detected for the NAO index series, the original Mann-Kendall's $\tau_{b}$ (Kendall and Gibbons 1990) has been applied for measuring trends of this atmospheric circulation mode.

Following Azorin-Molina et al. (2014; 2016), trend results have been reported at three different significance levels: 1) significant at $p<0.05,2$ ) significant at $p<0.10$, and 3) nonsignificant at $p>0.10$. Grades of $p$ level have been used to evaluate and focus on the importance and strength of the wind speed trends instead of having only one subjective $p$-level threshold (e.g., at $p<0.05$ ) that just highlights their statistical significance (Nicholls 2001; Azorin-Molina et al. 2014, 2016). This helps readers to evaluate trends from a "process and importance" perspective instead of only a "statistically significant" perspective. Furthermore, in order to evaluate whether the number of stations with significant trends have occurred by chance (Wilks 2006a), we evaluate the field significance of the detected significant trends-at $90 \%$ and $95 \%$ confidence levels - by applying both the Walker test (Katz 2002; Wilks 2006a) and the Bonferroni method (Johnson and Wichern 2002; Wilks 2006a,b).
TABLE 2. As in Table 1, but for monthly wind speed trends

\begin{tabular}{lcc}
\hline Month & $1956-2013$ & $1979-2008$ \\
\hline January & -0.00 & -0.02 \\
February & $\mathbf{- 0 . 0 4}$ & -0.13 \\
March & -0.00 & -0.23 \\
April & $\mathbf{- 0 . 1 0}$ & $\mathbf{- 0 . 1 7}$ \\
May & $\mathbf{- 0 . 0 6}$ & -0.06 \\
June & $\mathbf{- 0 . 0 8}$ & -0.01 \\
July & $\mathbf{- 0 . 0 9}$ & $\mathbf{- 0 . 1 7}$ \\
August & $\mathbf{- 0 . 1 3}$ & -0.19 \\
September & $\mathbf{- 0 . 0 8}$ & $\mathbf{- 0 . 2 4}$ \\
October & -0.06 & $\mathbf{- 0 . 2 5}$ \\
November & -0.06 & $\mathbf{- 0 . 2 9}$ \\
December & -0.07 & -0.22 \\
\hline
\end{tabular}

\section{Results}

\section{a. Annual, seasonal, and monthly wind speed trends}

Table 1 summarizes annual and seasonal wind speed trends for both the 58- and 30-yr periods. Annually, a negative trend of $-0.06 \mathrm{~m} \mathrm{~s}^{-1}$ decade $^{-1}$ has been found for 1956-2013 (and $-0.14 \mathrm{~m} \mathrm{~s}^{-1}$ decade $^{-1}$ for 1979-2008, both significant at $p<0.05$ ). Therefore, there was a statistically significant stilling for the regional wind speed series, and the magnitude of the shorter period is twice that of the longer period. Looking at the seasonality of the wind speed trends, two patterns can be identified: 1) a winter (DJF) pattern, which shows a declining trend for 1956-2013 and a small increasing trend for 1979-2008, and 2) a no-winter pattern occurring in spring (MAM), summer (JJA), and autumn (SON), which display large decreasing trends. In particular, a negative (but not significant at $p<0.10$ ) wind speed trend of $-0.04 \mathrm{~m} \mathrm{~s}^{-1}$ decade $^{-1}$ has been found in winter for 1956-2013, while a small positive tendency $\left(0.01 \mathrm{~m} \mathrm{~s}^{-1}\right.$ decade $^{-1}$, nonsignificant at $p<0.10$ ) is found for the same season during 1979 2008 period. On the contrary, a large decline (and statistically significant at $p<0.05$ ) has been detected during spring $\left(-0.06\right.$ and $-0.15 \mathrm{~m} \mathrm{~s}^{-1}$ decade $\left.^{-1}\right)$, summer $\left(-0.10\right.$ and $-0.11 \mathrm{~m} \mathrm{~s}^{-1}$ decade $\left.^{-1}\right)$, and autumn $(-0.07$ and $-0.26 \mathrm{~m} \mathrm{~s}^{-1}$ decade $\left.^{-1}\right)$. This suggests that the tendencies for the whole period 1956-2013 are reinforced in the 1979-2008 subperiod. On the one hand, the declining trend in winter for 1956-2013 is weakened by a slightly positive trend for 1979-2008; on the other hand, decreasing trends become even larger for the shortest period in spring, summer, and autumn.

Figure 4 illustrates the annual and seasonal wind speed anomalies averaged across Sweden for 1956-2013 (24 stations) and for 1979-2008 (33 stations). It is noteworthy to highlight the consistency between both regional series constructed by different number of stations, which shows the same temporal variability during the common 


\section{Wind speed trends 1956-2013}

$$
\begin{aligned}
& \text { Trends }\left(\mathrm{m} \mathrm{s}^{-1} \mathrm{dec}^{-1}\right) \\
& \triangle \geq 0.20 \\
& \triangle \geq 0.10 \text { and }<0.20 \\
& \triangle \geq 0.05 \text { and }<0.10 \\
& \Delta>0.00 \text { and }<0.05 \\
& =0.00 \\
& \nabla<0.00 \text { and }>-0.05 \\
& \nabla \leq-0.05 \text { and }>-0.10 \\
& \nabla \leq-0.10 \text { and }>-0.20 \\
& \nabla \leq-0.20
\end{aligned}
$$

White filled $=$ not significant at $p<0.10$ level Dark grey filled $=$ significant at $p<0.10$ level Black filled $=$ significant at $\mathrm{p}<0.05$ level

\section{(c) Spring (MAM)}

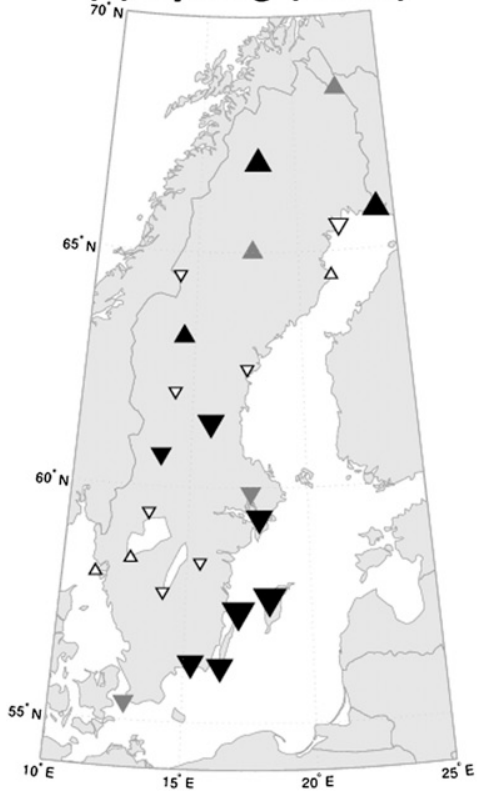

(a) Annual

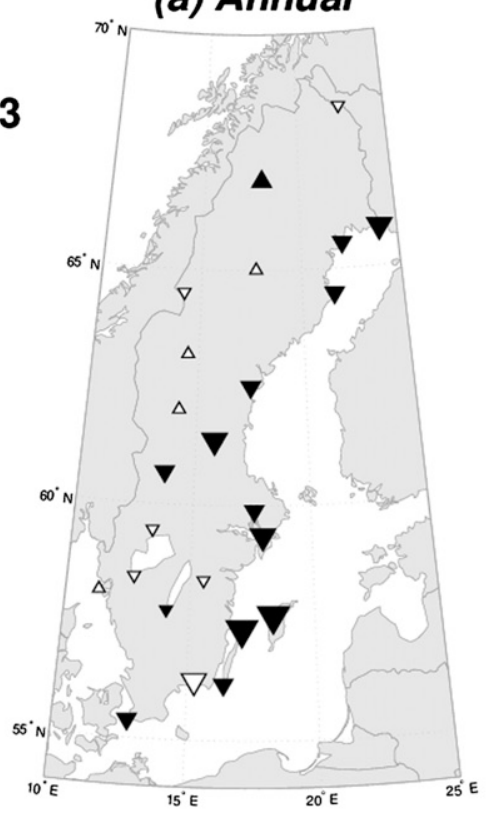

(d) Summer (JJA)

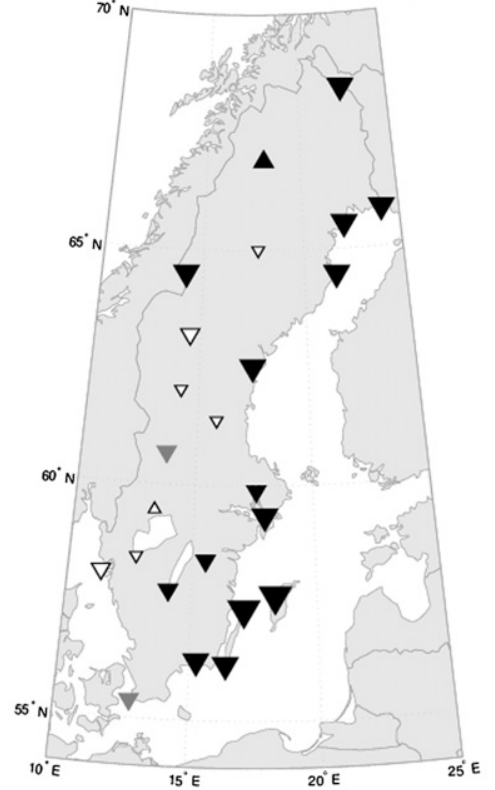

(b) Winter (DJF)

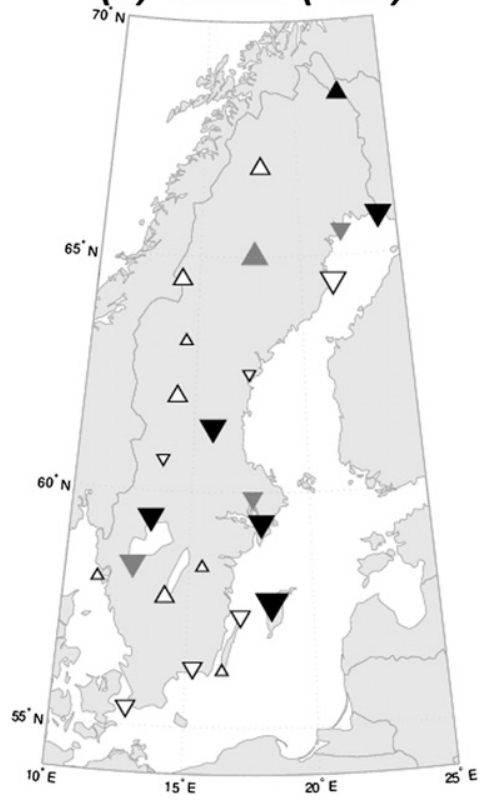

(e) Autumn (SON)

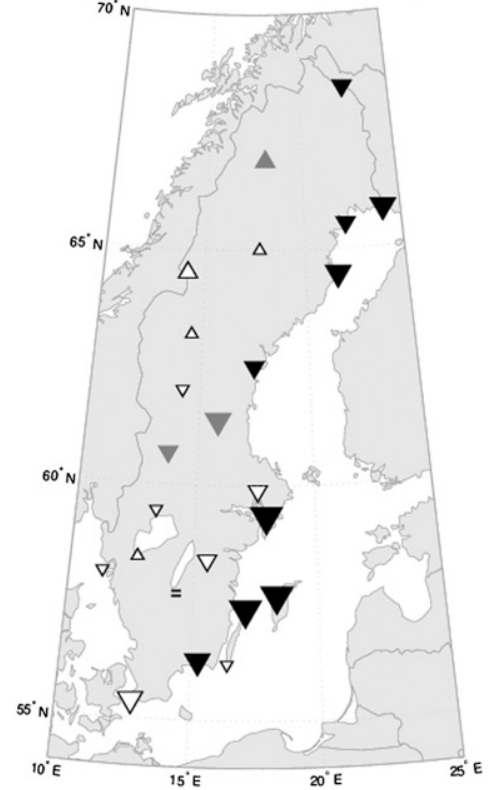

FIG. 5. Annual and seasonal spatial distribution of the sign and magnitude of trends $\left(\mathrm{m} \mathrm{s}^{-1} \mathrm{decade}^{-1}\right)$, and statistical significance (black filled triangles are significant at $p<0.05$, dark gray triangles are significant at $p<0.10$, and unfilled triangles are not significant at $p<0.10$ ) of wind speed trends for the homogenized series of the 24 stations for 1956-2013.

30-yr period. For revealing the annual and seasonal wind speed variability, the Gaussian low-pass filter (with $\sigma=4$ ) shows an almost identical feature (with some seasonal variations) for Figs. 4a-e. First, wind speed decreased until the 1960s-70s. Second, wind speed increased until the 1980s. Third, wind speed strongly declined during the last three decades, even though a recent weak increase was detected after around 2008. This seems to be a general pattern for all seasons, more evident for winter (which gives rise to the slightly positive trend in 1979-2008) and less clear for spring and summer.

Finally, Table 2 shows monthly trends for the two periods. In general, there is a dominance of declining trends for almost all months and the two periods, with 
TABLE 3. Annual and seasonal relative frequency ( $\%$ ) and number of stations in parentheses showing significant (at $p<0.05$ and $p<0.10)$ and nonsignificant (at $p>0.10$ ) negative and positive wind speed trends for the homogenized series of 1956-2013 (24 stations) and of 1979-2008 (33 stations). Also reported is the relative frequency of stations showing null trend $\left(0.000 \mathrm{~m} \mathrm{~s}^{-1} \mathrm{decade}^{-1}\right)$. For the three $p$ levels, relative frequencies are calculated with respect to the total number of stations showing negative or positive tendencies.

\begin{tabular}{|c|c|c|c|c|c|c|c|c|c|}
\hline Period & Negative & $\begin{array}{l}\text { Negative } \\
p<0.05\end{array}$ & $\begin{array}{l}\text { Negative } \\
p<0.10\end{array}$ & $\begin{array}{l}\text { Negative } \\
p>0.10\end{array}$ & Null & Positive & $\begin{array}{l}\text { Positive } \\
p<0.05\end{array}$ & $\begin{array}{l}\text { Positive } \\
p<0.10\end{array}$ & $\begin{array}{l}\text { Positive } \\
p>0.10\end{array}$ \\
\hline & & & & 1956-2013 & & & & & \\
\hline Annual & $79.2(19)$ & $68.4(13)$ & $68.4(13)$ & $31.6(6)$ & $0.0(0)$ & $20.8(5)$ & $20.0(1)$ & $20.0(1)$ & $80.0(4)$ \\
\hline Winter (DJF) & $58.3(14)$ & $35.7(5)$ & $57.1(08)$ & $42.9(6)$ & $0.0(0)$ & $41.7(10)$ & $10.0(1)$ & $20.0(2)$ & $80.0(8)$ \\
\hline Spring (MAM) & $70.8(17)$ & $47.1(8)$ & $58.8(10)$ & $41.2(7)$ & $0.0(0)$ & $29.2(7)$ & $28.6(2)$ & $57.1(4)$ & $42.9(3)$ \\
\hline Summer (JJA) & $91.7(22)$ & $63.6(14)$ & 72.7 (16) & $27.3(6)$ & $0.0(0)$ & $8.3(2)$ & $50.0(1)$ & $50.0(1)$ & $50.0(1)$ \\
\hline Autumn (SON) & 75.0 (18) & $50.0(9)$ & $61.1(11)$ & $\begin{array}{l}38.9(7) \\
1979-2008\end{array}$ & $4.2(1)$ & $20.8(5)$ & $0.0(0)$ & $20.0(1)$ & $80.0(4)$ \\
\hline Annual & $75.8(25)$ & $64.0(16)$ & $68.0(17)$ & $32.0(8)$ & $0.0(0)$ & $24.2(08)$ & 37.5 & 50. & $50.0(4)$ \\
\hline Winter (DJF) & $51.5(17)$ & $23.5(4)$ & $35.3(6)$ & $64.7(11)$ & $0.0(0)$ & $48.5(16)$ & $50.0(8)$ & $56.3(9)$ & $43.8(7)$ \\
\hline Spring (MAM) & $81.8(27)$ & $51.9(14)$ & $63.0(17)$ & $37.0(10)$ & $0.0(0)$ & $18.2(6)$ & $50.0(3)$ & $50.0(3)$ & $50.0(3)$ \\
\hline Summer (JJA) & $81.8(27)$ & 44.4 (12) & $48.1(13)$ & $51.9(14)$ & $0.0(0)$ & $18.2(6)$ & $33.3(2)$ & $33.3(2)$ & 66.7 (4) \\
\hline Autumn (SON) & $90.9(30)$ & $60.0(18)$ & $73.3(22)$ & $26.7(8)$ & $0.0(0)$ & $9.1(3)$ & $66.7(2)$ & $66.7(2)$ & $33.3(1)$ \\
\hline
\end{tabular}

only a few exceptions showing increasing trends in January, February, March, and June, in agreement with the positive trend detected in winter, particularly for the shortest period. Moreover, it is noticeable that statistically significant trends confirming the stilling are mostly concentrated from April to September for 1956-2013, switching to July-November for 1979-2008.

\section{b. Spatial distribution of wind speed trends}

The annual and seasonal spatial distribution of the sign, magnitude, and statistical significance of the trends for 1956-2013 is shown in Fig. 5, while the relative frequencies and actual station numbers are summarized in Table 3. In general, a characteristic spatial pattern with most negative and statistically significant trends located in the southern and eastern regions of Sweden has been found. The majority of these stations are located near the coast. On the contrary, observed wind speed changes are of lesser magnitude over the western inland stations compared to those from the eastern part of Sweden. Therefore, the largest and most statistically significant wind speed trends are mainly located in the southeastern part of the country. On the annual basis, wind speed declined at 19 of the 24 stations, with 13 stations showing statistically significant stilling at $p<0.05$. Wind speed increased at only 5 stations, with one of those trends showing a statistically significant trend at $p<0.05$. Seasonally, it is evident that wind stilling dominated in summer, with 22 of 24 stations displaying declining wind speed (14 stations significant at $p<0.05)$. Stilling was also important in spring (17 stations) and autumn (18 stations). In contrast, the declining trend of wind speed was smaller in winter, with 14 stations exhibiting stilling (5 stations statistically significant at $p<0.05$ ). Furthermore, increasing trends have been detected in only 2 of the 24 stations in summer. The highest number of stations (10) with positive trend is registered in winter (but only 1 station being significant at $p<0.05$ ), while for spring and autumn increasing trends are exhibited by 7 and 5 stations, respectively.

Annual and seasonal wind speed trends for the 30-yr subperiod of 1979-2008 are represented in Fig. 6, and a summary of the frequency and number results is also provided in Table 3. Overall, this subperiod shows similar features as in the 1956-2013 period, with most wind speed trends declining over the southern and eastern part of Sweden. However, the largest and most significant increasing trends are found over the stations located in the north. Annually, the number of stations displaying wind stilling is 25 (16 stations statistically significant at $p<0.05$ ), whereas 8 stations display increasing trends. Seasonally, the stilling is less widespread and statistically significant, occurring in 17 out of the 33 stations during winter (4 stations significant at $p<0.05)$. The most noticeable feature encountered in the 1979-2008 subperiod corresponds to the reinforcement of the positive tendency in winter, with a higher number of stations showing increases in wind speed compared to 1956-2013 (16 stations; 8 being statistically significant at $p<0.05)$. For the rest of the seasons, there is still a dominance of the declining trends, with greater percentages of statistically significant trends compared to 1956-2013, except for summer when stilling occurred at a smaller number of stations.

Both Walker and Bonferroni tests have showed field significance higher than the $90 \%$ confidence level for all significant (at $p<0.05$ and $p<0.10$ ) annual and seasonal trends reported in Table 3. In particular, for the 58-yr period of 1956-2013, 17 out of 19 stations of 


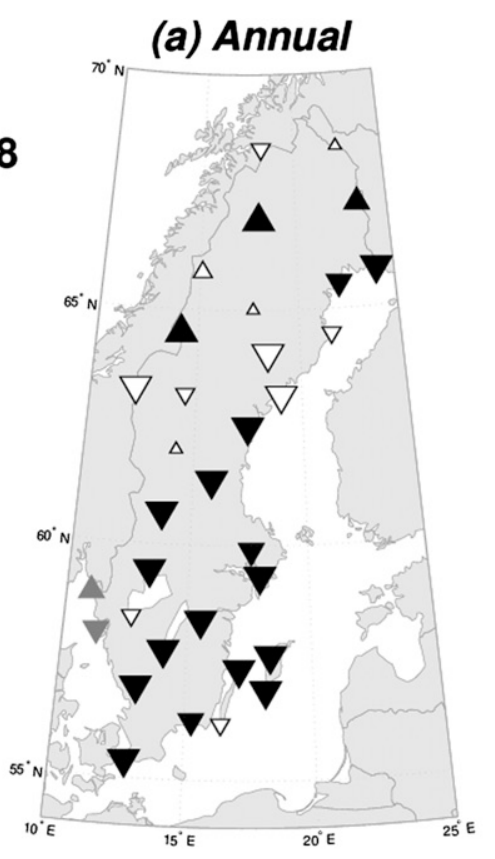

White filled $=$ not significant at $p<0.10$ level Dark grey filled $=$ significant at $p<0.10$ level Black filled $=$ significant at $p<0.05$ level

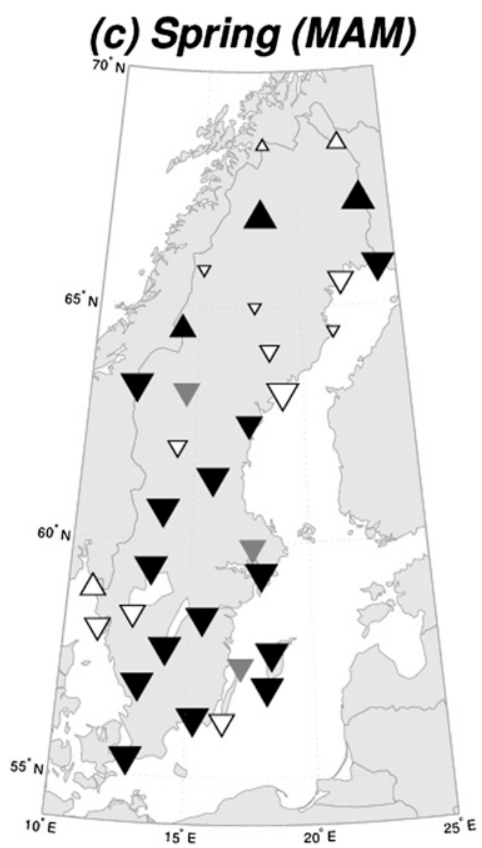

Wind speed trends 1979-2008

$$
\begin{aligned}
& \text { Trends }\left(\mathrm{m} \mathrm{s}^{-1} \mathrm{dec}^{-1}\right) \\
& \triangle \geq 0.20 \\
& \triangle \geq 0.10 \text { and }<0.20 \\
& \Delta \geq 0.05 \text { and }<0.10 \\
& \Delta>0.00 \text { and }<0.05 \\
& =0.00 \\
& \nabla<0.00 \text { and }>-0.05 \\
& \nabla \leq-0.05 \text { and }>-0.10 \\
& \nabla \leq-0.10 \text { and }>-0.20 \\
& \nabla \leq-0.20
\end{aligned}
$$
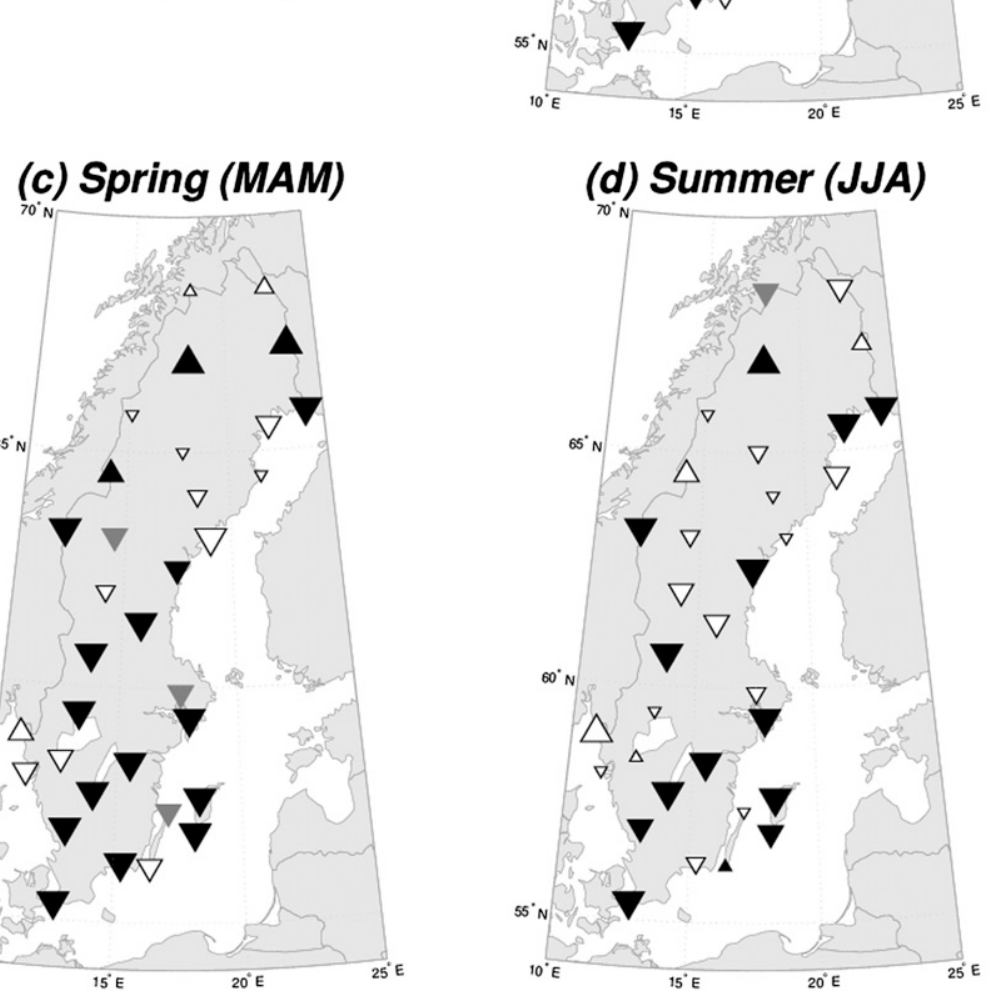

(b) Winter (DJF)

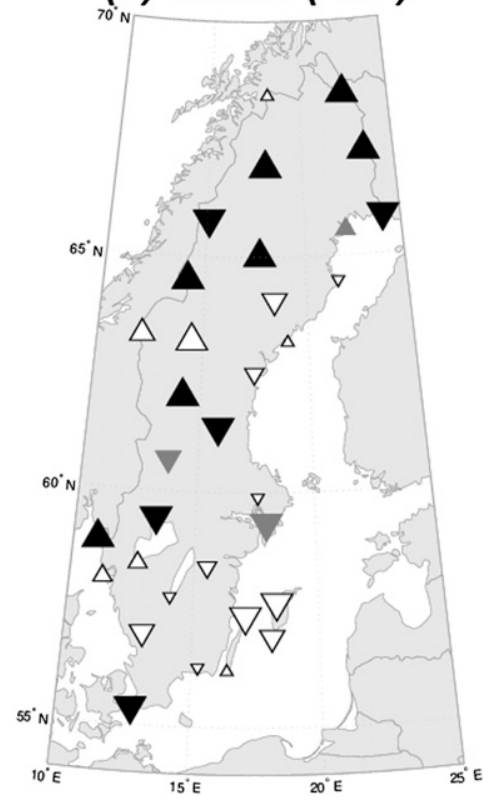

(e) Autumn (SON)

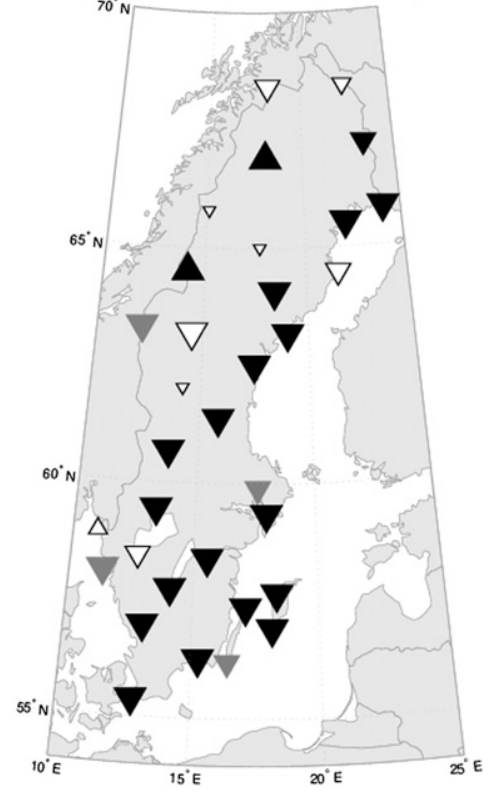

FIG. 6. As in Fig. 5, but for the 33 stations for 1979-2008.

the statistically significant multicomparisons have showed field significance higher than $95 \%$, while all the statistically significant trends for the 30-yr subperiod of 1979-2008 have displayed field significance higher than $95 \%$.

\section{c. Influence exerted by the $N A O$}

The impact of the NAO circulation mode on the wind speed variability has been investigated by quantifying the relationship between the observed wind speed anomaly dataset and the NAO index series. Table 4 displays the Pearson's correlation coefficient between both series at annual and seasonal bases. For the annual $(r=0.54$ and 0.40 for 1956-2013 and 1979-2008, respectively), winter ( $r=0.64$ and 0.55$)$, spring $(r=0.32$ and 0.47 ), and autumn ( $r=0.41$ and 0.52 ) periods, correlation coefficients are high and statistically significant at $p<0.05$ for both study periods, exhibiting the 
TABLE 4. Annual and seasonal Pearson's correlation coefficients between wind speed anomalies $\left(\mathrm{m} \mathrm{s}^{-1}\right)$ and the NAO index for 1956-2013 (24 stations) and 1979-2008 (33 stations). Statistically significant Pearson's correlation coefficients are shown in boldface for $p<0.05$ and in italic for $p<0.10$.

\begin{tabular}{lcc}
\hline \multicolumn{1}{c}{ Period } & $1956-2013$ & $1979-2008$ \\
\hline Annual & $\mathbf{0 . 5 4}$ & $\mathbf{0 . 4 0}$ \\
Winter (DJF) & $\mathbf{0 . 6 4}$ & $\mathbf{0 . 5 5}$ \\
Spring (MAM) & $\mathbf{0 . 3 2}$ & $\mathbf{0 . 4 7}$ \\
Summer (JJA) & 0.25 & 0.08 \\
Autumn (SON) & $\mathbf{0 . 4 1}$ & $\mathbf{0 . 5 2}$ \\
\hline
\end{tabular}

strongest relationship between the wind speed and the NAO index in winter. In contrast, this atmospheric circulation mode exerted a relatively weak influence in summer, with a Pearson's correlation coefficient of 0.25 during 1956-2013, only significant at $p<0.10$. For 1979 2008, summer exhibits even less influence $(r=0.08)$, not being statistically significant at $p<0.10$. To summarize, it is evident that the NAO exerts its major influence on wind speed anomalies in winter, followed by spring, autumn, and summer. A further comparison between the NAO index and the wind speed anomaly series is shown in Fig. S3 of the supplementary material.

The spatial distribution of annual and seasonal correlation coefficients between the NAO index and the wind speed anomalies across Sweden is displayed in Fig. 7 (1956-2013) and Fig. 8 (1979-2008), whereas Table 5 summarizes these results. Overall, the most interesting finding is that the NAO index drives wind speed variability across much of Sweden, particularly the southern region, causing the dominating positive relationships. For the 1956-2013 period (Fig. 7), 22 out of 24 stations have positive correlations with the NAO index on the annual and seasonal bases. The number of stations showing statistical significance for these positive relationships is high for the annual basis (16 stations at $p<0.05$ ), and particularly for winter (20 stations at $p<0.05$ ), covering much of the country. However, a smaller number of stations is found for the rest of seasons (9 stations for spring and autumn and 7 stations for summer, both at significant $p<0.05$ ), being mostly located in the southern and eastern part of Sweden. For the 1979-2008 subperiod (Fig. 8), the same spatial distribution of the relationships is evidenced. The most remarkable feature for this subperiod is the reinforcement of the influence of the NAO index, particularly in winter with all the 33 stations having positive correlations (27 of them being statistically significant at $p<0.05$ ). In contrast, summer is the season when the NAO index exerted the weakest influence, even though a great number of stations (22) are positively correlated (but only 3 of them being statistically significant at $p<0.05$ ). For the 58 -yr period of 1956-2013, 7 out of 8 stations of the statistically significant (at $p<0.05$ ) Pearson's correlation coefficients in Table 5 have showed field significance at the $95 \%$ confidence level, while all of them have field significance higher than $90 \%$. For the $30-\mathrm{yr}$ subperiod of 1979-2008, all the significant Pearson's correlation coefficients are field significant at the $95 \%$ confidence level.

Aiming at analyzing the impact of the NAO index on the reported trend and variability of wind speed, Table 6 summarizes the annual and seasonal tendencies of this atmospheric circulation mode for the both study periods. Annually, the NAO index slightly decreased during 1956-2013 ( -0.07 , nonsignificant at $p<0.10)$, turning to a large and statistically significant decline for 1979-2008 $(-0.20$, significant at $p<0.05)$. Seasonally, interesting differences in the sign and magnitude of change in the NAO index have been found. While the winter NAO index exhibited a positive tendency (nonsignificant at $p<0.10$ ), which means a strengthening of the positive phases and the associated westerly and southwesterly winds, large negative trends dominated for all the other seasons, which is consistent with the observed stilling. Therefore, the reported decadal variability of wind speed across Sweden can to a large extent be explained by the NAO index.

\section{Summary and discussion}

In this study linear trend and multidecadal variability of observed near-surface wind speed across Sweden have been assessed to investigate the wind variability in the mid- to high-latitude region. Anemometer observations from a total of 33 land-based weather stations across Sweden have been used to assess multidecadal wind speed change for 1956-2013 (24 stations), with a focus on the 1979-2008 subperiod (33 stations). As the observed wind speed series showed a close relationship with geostrophic winds estimated from the pressure measurements, the observed near-surface wind data have been homogenized with the geowind speed as reference series. Specifically, the robust data processing protocol proposed by Azorin-Molina et al. (2014) has been followed to create homogenized wind speed data, which was then subjected to the trend and variability analyses.

The results achieved in this investigation show an overall statistically significant downward trend in the wind speed over Sweden for both 1956-2013 and 1979-2008 periods. However, this study also provides a novel finding with regard to seasonal differences in the change of wind speed: while large declining values have been observed in 
1956-2013

(†) Positive correlation and significant at $p<0.05$

(†) Positive correlation and significant at $p<0.10$

+ Positive correlation but not significant at $p<0.10$

(1) Negative correlation and significant at $p<0.05$ (1) Negative correlation and significant at $p<0.10$

V Negative correlation but not significant at $p<0.10$

O Null Pearson's correlation coefficient

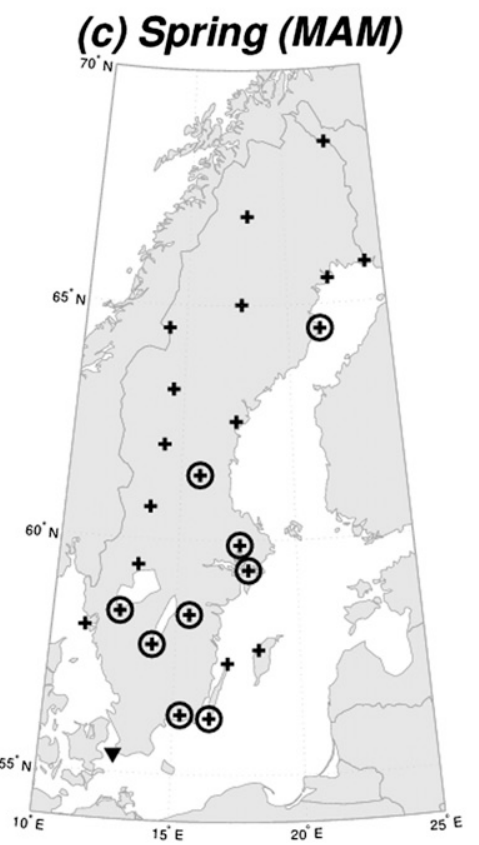

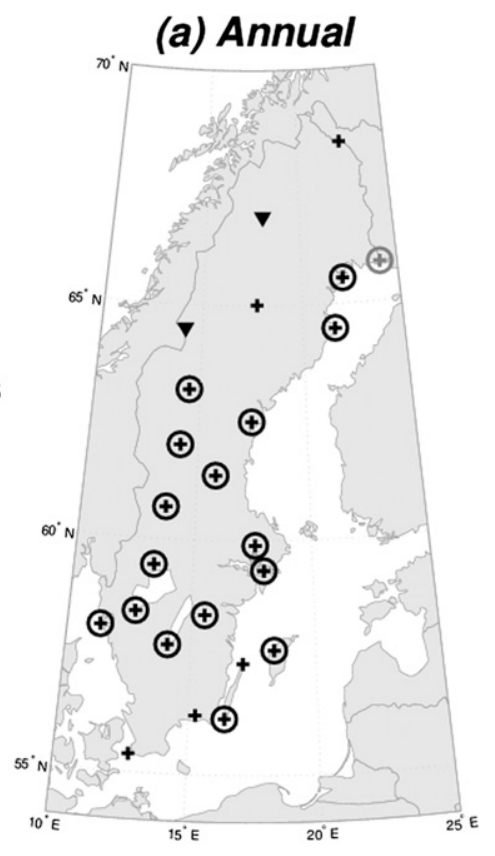

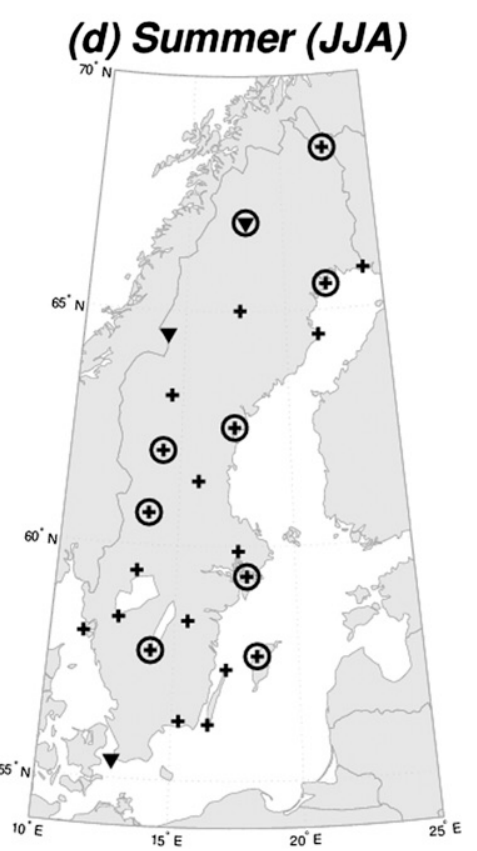

(b) Winter (DJF)

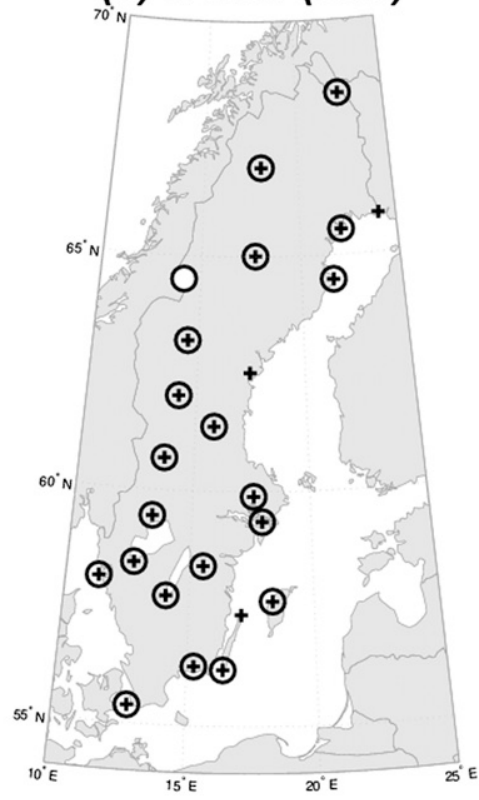

(e) Autumn (SON)

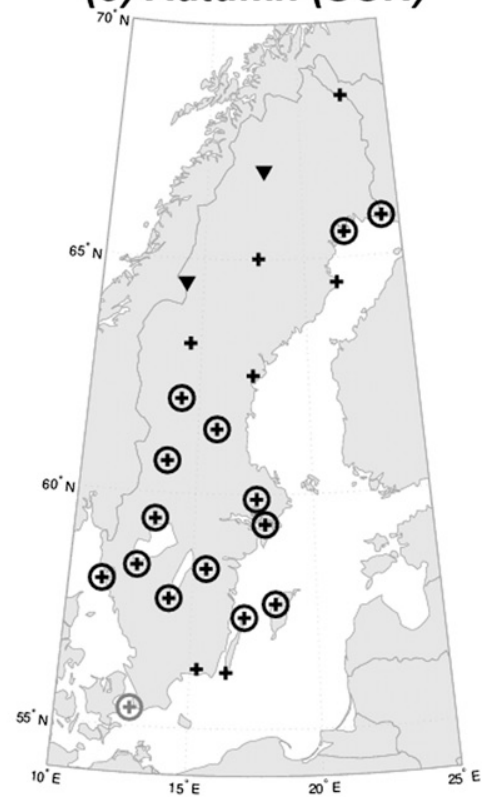

FIG. 7. Spatial distribution of the sign and significance of Pearson's correlation relationship between the wind speed anomalies $\left(\mathrm{m} \mathrm{s}^{-1}\right)$ and the NAO index on the annual and seasonal bases for 1956-2013 (24 stations).

spring, summer, and autumn, a weak (nonsignificant) increase of wind speed in winter was detected across the country for 1979-2008. This result is different from most of the previous wind studies conducted on midlatitude regions (McVicar et al. 2012), where the strongest stilling was reported in winter (Vautard et al. 2010). Moreover, the atmospheric stilling was much more significant over coastal stations and the southern part of
Sweden and was observed in a higher proportion of stations in summer.

Even though trends are sensitive to the length of the study period (McVicar et al. 2010; Troccoli et al. 2012), comparison with the results of other studies covering regions of a similar latitude range as Sweden reveals that the detected decreasing trend for Sweden during 1956-2013 $\left(-0.06 \mathrm{~m} \mathrm{~s}^{-1}\right.$ decade $\left.^{-1}\right)$ is in line 
1979-2008

(†) Positive correlation and significant at $\mathrm{p}<0.05$

(†) Positive correlation and significant at $p<0.10$

+ Positive correlation but not significant at $p<0.10$

(1) Negative correlation and significant at $\mathrm{p}<0.05$ (1) Negative correlation and significant at $p<0.10$

$\nabla$ Negative correlation but not significant at $p<0.10$

O Null Pearson's correlation coefficient

(c) Spring (MAM)

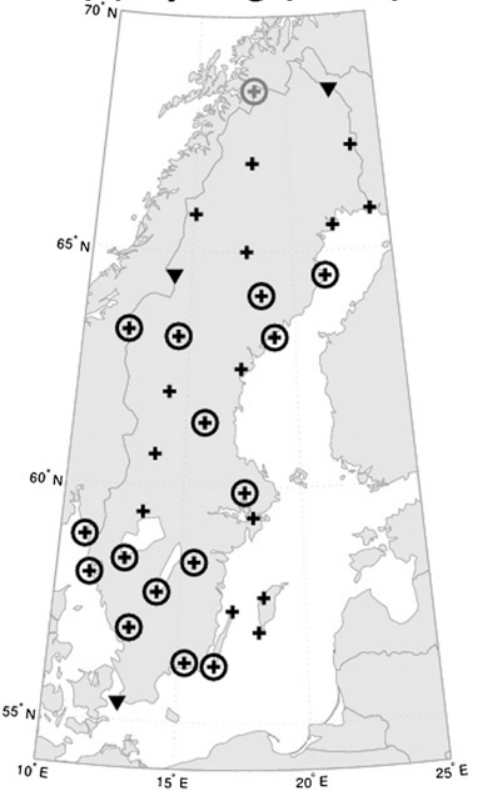

(a) Annual

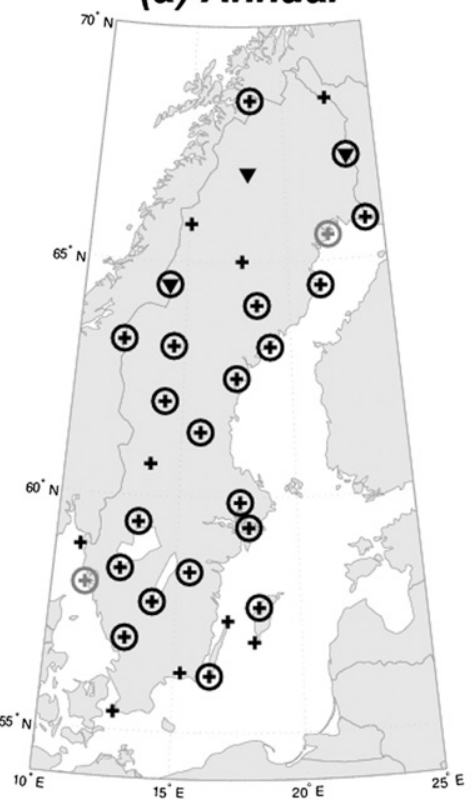

(d) Summer (JJA)

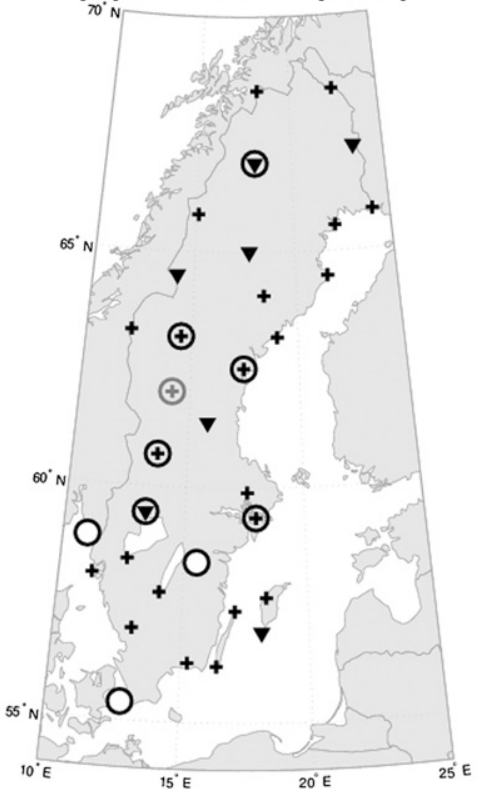

(b) Winter (DJF)

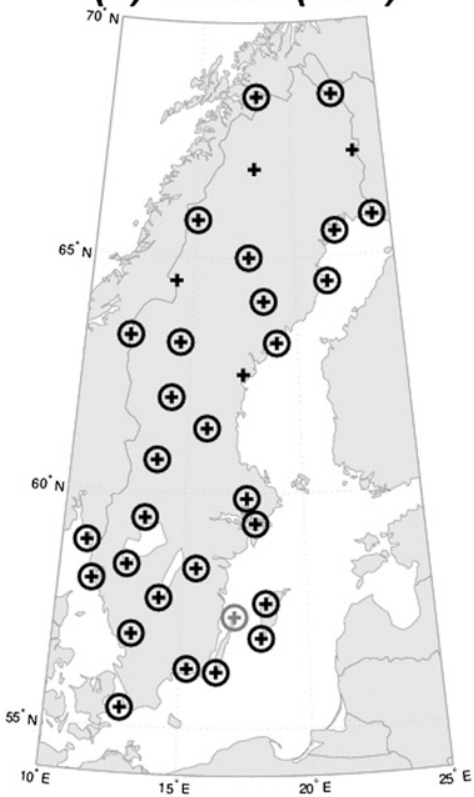

(e) Autumn (SON)

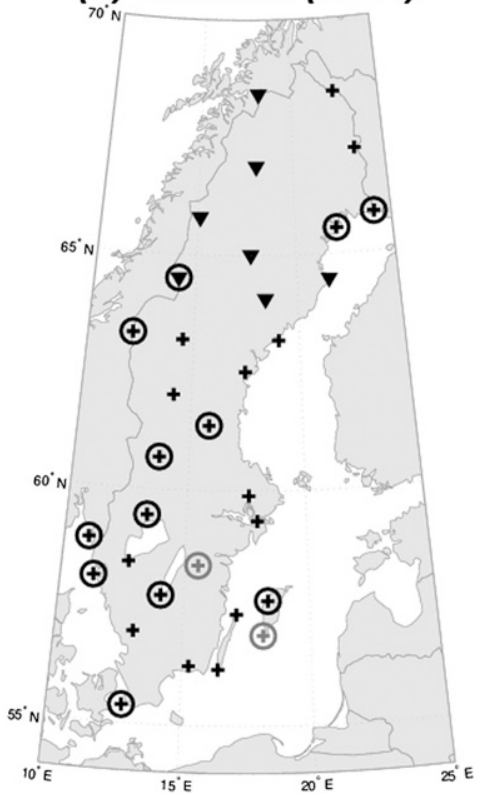

FIG. 8. As in Fig. 7, but for the 33 stations for 1979-2008.

with the one observed in Canada $\left(42^{\circ}-71^{\circ} \mathrm{N}\right)$ by Wan et al. (2010) for 1953-2006 $\left(-0.05 \mathrm{~m} \mathrm{~s}^{-1}\right.$ decade $\left.^{-1}\right)$ and the stilling reported in the Netherlands $\left(51^{\circ}-53^{\circ} \mathrm{N}\right.$, country to the southwest of Sweden) between 1970 and 2010 by Cusack $(2013)\left(-0.09 \mathrm{~m} \mathrm{~s}^{-1}\right.$ decade $\left.^{-1}\right)$. Only the $-0.16 \mathrm{~m} \mathrm{~s}^{-1}$ decade $^{-1}$ detected trend for Russia $\left(40^{\circ}-74^{\circ} \mathrm{N}\right)$ during $1936-2006$ (Gruza et al. 2008) is 2 times larger than the one detected for Sweden. For 1979-2008, the overall large declining trend detected for
Sweden $\left(-0.14 \mathrm{~m} \mathrm{~s}^{-1}\right.$ decade $\left.^{-1}\right)$ is approximately 1.5 times higher than that reported for the same period by Vautard et al. (2010) across Europe $\left(-0.09 \mathrm{~m} \mathrm{~s}^{-1} \mathrm{decade}^{-1}\right)$, and it is even 15 times larger than the one detected by Azorin-Molina et al. (2014) for the Iberian Peninsula $\left(-0.01 \mathrm{~m} \mathrm{~s}^{-1}\right.$ decade $^{-1}$, in particular $-0.01 \mathrm{~m} \mathrm{~s}^{-1}$ decade $^{-1}$ for Spain and $-0.04 \mathrm{~m} \mathrm{~s}^{-1}$ decade $^{-1}$ for Portugal). As atmospheric circulation over southern Europe is primarily characterized by weak winds under the influence 
TABLE 5. Relative frequency ( $\%$ ) and number of stations in parentheses showing negative, positive, null, and significant (at $p<0.05$ ) Pearson's correlation coefficients between wind speed anomalies $\left(\mathrm{m} \mathrm{s}^{-1}\right)$ and the NAO index annually and seasonally for $1956-2013$ (24 stations) and for 1979-2008 (33 stations). For the $0.05 p$-level significance, relative frequencies are calculated with respect to the total number of stations showing negative or positive tendencies.

\begin{tabular}{|c|c|c|c|c|c|}
\hline Period & Negative & Negative $p<0.05$ & Null & Positive & Positive $p<0.05$ \\
\hline & & & 1956-2013 & & \\
\hline Annual & $8.3(2)$ & $0.0(0)$ & $0.0(0)$ & $91.7(22)$ & $72.7(16)$ \\
\hline Winter (DJF) & $0.0(0)$ & $0.0(0)$ & $4.2(1)$ & $95.8(23)$ & $87.0(20)$ \\
\hline Spring (MAM) & $4.2(1)$ & $0.0(0)$ & $0.0(0)$ & $95.8(23)$ & $39.1(9)$ \\
\hline Summer (JJA) & $12.5(3)$ & $33.3(1)$ & $0.0(0)$ & $87.5(21)$ & $33.3(7)$ \\
\hline \multirow[t]{2}{*}{ Autumn (SON) } & $8.3(2)$ & $0.0(0)$ & $0.0(0)$ & $91.7(22)$ & $42.9(9)$ \\
\hline & & & 1979-2008 & & \\
\hline Annual & $9.1(3)$ & $66.7(2)$ & $0.0(0)$ & $90.9(30)$ & $63.4(19)$ \\
\hline Winter (DJF) & $0.0(0)$ & $0.0(0)$ & $0.0(0)$ & $100.0(33)$ & $81.8(27)$ \\
\hline Spring (MAM) & $9.1(3)$ & $0.0(0)$ & $0.0(0)$ & $90.9(30)$ & $50.0(15)$ \\
\hline Summer (JJA) & $24.2(8)$ & $12.5(1)$ & $9.1(3)$ & $66.7(22)$ & $13.6(3)$ \\
\hline Autumn (SON) & $21.2(7)$ & $14.3(1)$ & $0.0(0)$ & $78.8(26)$ & $42.3(11)$ \\
\hline
\end{tabular}

of the subtropical high pressure belt, the stilling is of small magnitude (e.g., Spain and Portugal), while surface wind speed over northern midlatitudes in Europe (e.g., the Scandinavian Peninsula), which is under the influence of storm tracks that are related to the polar jet stream (Smits et al. 2005), has markedly decreased.

The latitudinal dependence of the wind speed variability observed across Sweden - that is, larger decreasing trends dominate the southern part of the country while they become smaller (even positive) for higher latitudes-is in line with trends from model projections and observations from terrestrial anemometers, which show negative wind speed trends at midlatitudes and positive wind speed trends at high latitudes (Vautard et al. 2010; McVicar et al. 2012). The pattern with regionally averaged wind speed declines at midlatitudes and increases at high latitudes is hypothetically associated with the poleward expansion of the Hadley cell (HC) and consequent change in (i) the pressure gradients (in response to global warming) and (ii) the observed increasing height of the tropopause (Santer et al. 2003; Lu et al. 2007; McVicar et al. 2008; Yin et al. 2009). In view of these findings across Sweden and the previous results from other studies, two latitudinal dependence patterns for the stilling are evident-across Sweden, smaller negative trends (or even positive) for higher latitudes compared to the southern regions. Based on these observations, moving from the subtropical regions toward the North Pole, first relatively weak stilling should be found (southern Europe); then, for higher latitudes, large decreasing is expected to dominate (as for southern Sweden); thereafter, moving closer to the Arctic Circle, stilling becomes weaker and eventually an increasing trend can be a general feature.

A comparison against the recent results of AzorinMolina et al. (2014) from southern Europe reveals that the less negative and not significant decreasing trend for
Sweden during winter (even positive for 1979-2008) is opposite to the large negative tendency in Spain and Portugal. In addition, the seasonal distribution of the stations showing positive and negative trends in Sweden is different from the one identified by Azorin-Molina et al. (2014) for Spain and Portugal. Whereas the wind decreasing for Sweden is mainly observed in summer, the summer in the Iberian Peninsula is the season with the highest rate of increasing wind speed (also for daily peak wind gusts; Azorin-Molina et al. 2016). The findings of this study indicate that the detected positive NAO index trend in winter for 1956-2013 and 1979-2008 is behind the seasonal differences in the magnitude and sign of wind trends between northern and southern Europe, in particular the observed opposite features evidenced for winter. In fact, this positive tendency of the NAO index during winter forces low pressure systems to travel northward, while anticyclonic circulations dominate southern Europe. Therefore, for high latitudes such as Sweden, the result is an increase in winter near-surface wind speed (opposite to the general stilling), whereas this positive NAO index trend forces a marked slowdown of wind speed in the midlatitudes of southern Europe in winter, as detected by Azorin-Molina et al. $(2014,2016)$

TABLE 6. Annual and seasonal trends of the NAO index for 1956-2013 and 1979-2008. Values are expressed as standardized sea level pressure difference. Statistically significant trends are shown in boldface for $p<0.05$ and in italic for $p<0.10$.

\begin{tabular}{lcc}
\hline \multicolumn{1}{c}{ Period } & $1956-2013$ & $1979-2008$ \\
\hline Annual & -0.07 & $\mathbf{- 0 . 2 0}$ \\
Winter (DJF) & -0.10 & -0.11 \\
Spring (MAM) & -0.07 & -0.02 \\
Summer (JJA) & -0.14 & $\mathbf{- 0 . 4 6}$ \\
Autumn (SON) & $\mathbf{- 0 . 1 7}$ & $\mathbf{- 0 . 3 5}$ \\
\hline
\end{tabular}


for Spain and Portugal. Osborn (2011) suggested that it may be the increasing anthropogenic forcing (e.g., greenhouse gases) that forces a shift of atmospheric circulation toward positive NAO index phases. This observed decadal increase in the winter NAO index seems to be responsible for much of the changes in prevailing wintertime surface wind speeds across Sweden and Europe. Moreover, Previdi and Liepert (2007) showed that an increase in the Northern Hemisphere annular mode, closely correlated to the NAO, is associated with a poleward expansion of the tropical Hadley cell and subtropical dry zones, which causes a poleward shift of midlatitudes storm tracks. Increased NAO index could then be linked to the poleward expansion of Hadley cell, showing again the shifted Hadley cell can be one of the causes responsible for the detected wind stilling across Sweden.

To conclude, the strong influence of large-scale atmospheric circulation on the observed near-surface wind speed variability across Sweden is confirmed, although the exact quantification of various plausible causes of the stilling remains to be determined. The poleward expansion of the Hadley cell is a hypothetical cause of the detected wind speed pattern across the country. Azorin-Molina et al. $(2014,2016)$ also attributed much of the wind speed trends to decadal variability of some atmospheric circulation indices. However, further research is needed to significantly improve our limited knowledge on the role played by the atmospheric circulation (analyzing other large-scale synoptic indices and, e.g., shifts in prevailing wind direction patterns) and other potential factors (e.g., land surface roughness, instrumental drifts, sunlight dimming, and atmospheric stability changes) in driving the spatiotemporal differences in wind speed changes under a climate change scenario. This study also highlights the importance of reviving and homogenizing wind speed datasets prior to the 1960s (Iacono and Azorin-Molina 2014), which would provide a unique opportunity to examine wind speed trends and causes of the global stilling on longer time periods than previous studies.

Acknowledgments. This research contributes to the strategic research areas Modelling the Regional and Global Earth system (MERGE) and Biodiversity and Ecosystem services in a Changing Climate (BECC). D. Chen is supported by a grant from the Swedish Research Council (2014-5320). C. Azorin-Molina is granted by the postdoctoral fellowship JCI-2011-10263. The authors wish to thank SMHI for providing the observed wind speed data and particularly Leif Hallingfors and AnnChristine Andersson of the SMHI Observations Corse
Service, who respectively supplied important information regarding the QC procedures applied by SMHI and photos of the anemometer instrumentation adopted by SMHI before 1995. The authors would also like to thank Lennart Wern and Lars Bärring from SMHI, who provided the geowind series used for the homogenization procedure. The authors are very grateful to the three anonymous reviewers for their constructive and helpful comments to the original manuscript.

\section{REFERENCES}

Achberger, C., D. Chen, and H. Alexandersson, 2006: The surface winds of Sweden during 1999-2000. Int. J. Climatol., 26, 159-178, doi:10.1002/joc.1254.

Aguilar, E., I. Auer, M. Brunet, T. C. Peterson, and J. Wieringa, 2003: Guidelines on climate metadata and homogenization. World Meteorological Organization Tech. Doc. WMO/TD-1186, 52 pp. [Available online at http://www.wmo.int/datastat/ documents/WCDMP-53_1.pdf.]

Alexandersson, H., 1986: A homogeneity test to precipitation data. Int. J. Climatol., 6, 661-675, doi:10.1002/joc.3370060607. 2006: Vindstatistikför Sverige 1961-2004 (in Swedish). Swedish Meteorological and Hydrological Institute Rep. Meteorologi 121, 47 pp. [Available online at http://www.smhi. se/polopoly_fs/1.1895!/meteorologi_121-06\%5B1\%5D.pdf.]

Azorin-Molina, C., and Coauthors, 2014: Homogenization and assessment of observed near-surface wind speed trends over Spain and Portugal, 1961-2011. J. Climate, 27, 3692-3712, doi:10.1175/JCLI-D-13-00652.1.

, J. A. Guijarro, T. R. McVicar, S. M. Vicente-Serrano, D. Chen, S. Jerez, and F. Espírito-Santo, 2016: Trends of daily peak wind gusts in Spain and Portugal, 1961-2014. J. Geophys. Res. Atmos., 121, 1059-1078, doi:10.1002/2015JD024485.

Borne, K., D. Chen, and M. Nunez, 1998: A method for finding sea breeze days under stable synoptic conditions and its application to the Swedish west coast. Int. J. Climatol., 18, 901-914, doi:10.1002/(SICI)1097-0088(19980630)18:8<901:: AID-JOC295>3.0.CO;2-F.

Brázdil, R., K. Chromá, P. Dobrovolný, and R. Tolasz, 2009: Climate fluctuations in the Czech Republic during the period 1961-2005. Int. J. Climatol., 29, 223-242, doi:10.1002/joc.1718.

Chen, D., 2000: A monthly circulation climatology for Sweden and its application to a winter temperature case study. Int. J. Climatol., 20, 1067-1076, doi:10.1002/1097-0088(200008)20:10<1067:: AID-JOC528>3.0.CO;2-Q.

_ , and C. Hellström, 1999: The influence of the North Atlantic Oscillation on the regional temperature variability in Sweden: spatial and temporal variations. Tellus, 51A, 505-516, doi:10.1034/j.1600-0870.1999.t01-4-00004.x.

Cusack, S., 2013: A 101 year record of windstorms in the Netherlands. Climatic Change, 116, 693-704, doi:10.1007/ s10584-012-0527-0.

El Kenawy, A., J. I. López-Moreno, P. Stepanek, and S. M. Vicente-Serrano, 2013: An assessment of the role of homogenization protocol in the performance of daily temperature series and trends: Application to northeastern Spain. Int. J. Climatol., 33, 87-108, doi:10.1002/joc.3410.

Fu, G., J. Yu, Y. Zhang, S. Hu, R. Ouyang, and W. Liu, 2011: Temporal variation of wind speed in China for 1961-2007. Theor. Appl. Climatol., 104, 313-324, doi:10.1007/s00704-010-0348-x. 
Gilbert, R. O., 1987: Statistical Method for Environmental Pollution Monitoring. Van Nostrand Reinhold Co., 320 pp.

Göktürk, O. M., D. Bozkurt, O. L. Sen, and M. Karaca, 2008: Quality control and homogeneity of Turkish precipitation data. Hydrol. Processes, 22, 3210-3218, doi:10.1002/ hyp. 6915.

Gower, J. F. R., 2002: Temperature, wind and wave climatologies, and trends from marine meteorological buoys in the northeast Pacific. J. Climate, 15, 3709-3718, doi:10.1175/ 1520-0442(2002)015<3709:TWAWCA > 2.0.CO;2.

Gruza, G. V., and Coauthors, 2008: Assessment report on climate change and their impact on the territory of the Russian Federation (in Russian). Voeikov Main Geophysical Observatory (MGO), Institute of Global Climate and Ecology, Roshydromet, and Russian Academy of Sciences (IGCE) Rep., 31-87. [Available online at http://climate2008.igce.ru/v2008/v1/vI-3.pdf.]

Guo, H., M. Xu, and Q. Hu, 2011: Changes in near-surface wind speed in China: 1969-2005. Int. J. Climatol., 31, 349-358, doi:10.1002/joc.2091.

Hamed, K. H., and A. R. Rao, 1998: A modified Mann-Kendall trend test for autocorrelated data. J. Hydrol., 204, 182-196, doi:10.1016/S0022-1694(97)00125-X.

Hanssen-Bauer, I., and E. Førland, 2000: Temperature and precipitation variations in Norway 1990-1994 and their links to atmospheric circulation. Int. J. Climatol., 20, 1693-1708, doi:10.1002/1097-0088(20001130)20:14<1693:: AID-JOC567>3.0.CO;2-7.

Hartmann, B., and G. Wendler, 2005: The significance of the 1976 Pacific climate shift in the climatology of Alaska. J. Climate, 18, 4824-4839, doi:10.1175/JCLI3532.1.

Hurrell, J. W., and H. van Loon, 1997: Decadal variations in climate associated with the North Atlantic Oscillation. Climatic Change, 36, 301-326, doi:10.1023/A:1005314315270.

Iacono, M. J., and C. Azorin-Molina, 2014: Long-term declining trends in historical wind measurements at the Blue Hill Meteorological Observatory, 1885-2013. A GU Fall Meeting 2014, San Francisco, CA, Amer. Geophys. Union, doi:10.13140/ 2.1.3549.6000.

Johnson, R. A., and D. W. Wichern, 2002: Applied Multivariate Statistical Analysis. 5th ed. Prentice Hall, 767 pp.

Jones, P. D., T. Jonsson, and D. Wheeler, 1997: Extension to the North Atlantic Oscillation using early instrumental pressure observations from Gibraltar and south-west Iceland. Int. J. Climatol., 17, 1433-1450, doi:10.1002/(SICI)1097-0088(19971115)17:13<1433:: AID-JOC203>3.0.CO;2-P.

Jönsson, P., and K. Fortuniak, 1995: Interdecadal variations of surface wind direction in Lund, southern Sweden, 1741-1990. Int. J. Climatol., 15, 447-461, doi:10.1002/joc.3370150407.

Karmeshu, N., 2012: Trend detection in annual temperature and precipitation using the Mann Kendall test-A case study to assess climate change on select states in the northeastern United States. M.S. thesis, Dept. of Earth and Environmental Science, University of Pennsylvania, 22 pp. [Available online at http://repository.upenn.edu/mes_capstones/47/.]

Katz, R. W., 2002: Sir Gilbert Walker and a connection between El Niño and statistics. Stat. Sci., 17, 97-112, doi:10.1214/ss/1023799000.

Kendall, M. G., and J. D. Gibbons, 1990: Rank Correlation Methods. Oxford University Press, 272 pp.

Klink, K., 1999: Trends in mean monthly maximum and minimum surface wind speeds in the coterminous United States, 1961 to 1990. Climate Res., 13, 193-205, doi:10.3354/cr013193.

Linderholm, H. W., T. Ou, J. Jeong, C. K. Folland, D. Gong, H. Liu, Y. Liu, and D. Chen, 2011: Interannual teleconnections be- tween the summer North Atlantic Oscillation and the East Asian summer monsoon. J. Geophys. Res., 116, D13107, doi:10.1029/2010JD015235.

Lu, J., G. A. Vecchi, and T. Reichler, 2007: Expansion of the Hadley cell under global warming. Geophys. Res. Lett., 34, L06805, doi:10.1029/2006GL028443.

Lynch, A. H., J. A. Curry, R. D. Brunner, and J. A. Maslanik, 2004: Toward an integrated assessment of the impacts of extreme wind events on Barrow, Alaska. Bull. Amer. Meteor. Soc., 85 , 209-221, doi:10.1175/BAMS-85-2-209.

Martyn, D., 1992: Climates of the World. Elsevier, 435 pp.

McVicar, T. R., T. G. Van Niel, L. T. Li, M. L. Roderick, D. P. Rayner, L. Ricciardulli, and R. J. Donohue, 2008: Wind speed climatology and trends for Australia, 1975-2006: Capturing the stilling phenomenon and comparison with near-surface reanalysis output. Geophys. Res. Lett., 35, L20403, doi:10.1029/ 2008GL035627.

-, M. L. Roderick, L. T. Li, X. G. Mo, N. E. Zimmermann, and D. R. Schmatz, 2010: Observational evidence from two mountainous regions that near-surface wind speeds are declining more rapidly at higher elevations than lower elevations: 1960-2006. Geophys. Res. Lett., 37, L06402, doi:10.1029/ 2009GL042255.

— , and Coauthors, 2012: Global review and synthesis of trends in observed terrestrial near-surface wind speeds: Implications for evaporation. J. Hydrol., 416-417, 182-205, doi:10.1016/ j.jhydrol.2011.10.024.

Nicholls, N., 2001: The insignificance of significance testing. Bull. Amer Meteor. Soc., 82, 981-986, doi:10.1175/1520-0477(2001)082<0981: CAATIO $>2.3 . \mathrm{CO} ; 2$.

Osborn, T. J., 2011: Variability and changes in the North Atlantic Oscillation index. Hydrological, Socioeconomic and Ecological Impacts of the North Atlantic Oscillation in the Mediterranean Region, S. M. Vicente-Serrano and R. M. Trigo, Eds., Advances in Global Change Research Series, Vol. 46, Springer, 9-22.

Previdi, M., and B. G. Liepert, 2007: Annular modes and Hadley cell expansion under global warning. Geophys. Res. Lett., 34, L22701, doi:10.1029/2007GL031243.

Pryor, S. C., R. J. Barthelmie, and E. S. Riley, 2007: Historical evolution of wind climates in the USA. J. Phys. Conf. Ser., $\mathbf{7 5}$, 012065, doi:10.1088/1742-6596/75/1/012065.

_- and Coauthors, 2009: Wind speed trends over the contiguous United States. J. Geophys. Res., 114, D14105, doi:10.1029/ 2008JD011416.

Rissanen, P., C. Jacobsson, H. Madsen, M. Moe, T. Palsdottir, and F. Vejen, 2000: Nordic methods for quality control of climate data. Norwegian Meteorological Institute Rep. 10/00 Klima, 50 pp. [Available online at http://www.smhi.se/hfa_coord/ nordklim/old/report10_00.pdf.]

Roderick, M. L., L. D. Rotstayn, G. D. Farquhar, and M. T. Hobbins, 2007: On the attribution of changing pan evaporation. Geophys. Res. Lett., 34, L17403, doi:10.1029/2007GL031166.

Santer, B. D., and Coauthors, 2003: Contributions of anthropogenic and natural forcing to recent tropopause height changes. Science, 301, 479-483, doi:10.1126/science.1084123.

Smits, A., A. M. G. Klein-Tank, and G. P. Können, 2005: Trends in storminess over the Netherlands, 1962-2002. Int. J. Climatol. 25, 1331-1344, doi:10.1002/joc.1195.

Stepanek, P., 2004: Anclim: Software for time series analysis and homogenization. Dept. of Geography, Faculty of Natural Science, Masaryk University. [Available online at http://www. climahom.eu/software-solution/anclim.] 
Thomas, B. R., E. C. Kent, V. R. Swail, and D. I. Berry, 2008: Trends in ship wind speeds adjusted for observation method and height. Int. J. Climatol., 28, 747-763, doi:10.1002/joc.1570.

Troccoli, A., K. Muller, P. Coppin, R. Davy, C. Russell, and A. L. Hirsch, 2012: Long-term wind speed trends over Australia. J. Climate, 25, 170-183, doi:10.1175/2011JCLI4198.1.

Vautard, R., J. Cattiaux, P. Yiou, J.-N. Thépaut, and P. Ciais, 2010: Northern Hemisphere atmospheric stilling partly attributed to an increase in surface roughness. Nat. Geosci., 3, 756-761, doi:10.1038/ngeo979.

von Storch, H., 1995: Misuses of statistical analysis in climate research. Analysis of Climate Variability: Applications of Statistical Techniques, H. von Storch and A. Navarra, Eds., Springer, 11-26.

Wallace, J. M., and D. S. Gutzler, 1981: Teleconnections in the geopotential height field during the Northern Hemisphere winter. Mon. Wea. Rev., 109, 784-812, doi:10.1175/ 1520-0493(1981)109<0784:TITGHF >2.0.CO;2.

Wan, H., L. W. Xiaolan, and V. R. Swail, 2010: Homogenization and trend analysis of Canadian near-surface wind speeds. J. Climate, 23, 1209-1225, doi:10.1175/2009JCLI3200.1.

Wern, L., and L. Bärring, 2009: Sverige vindklimat 1901-2008: Analys av trend i geostrofisk vind (in Swedish). Swedish Meteorological and Hydrological Institute Rep. Meteorologi
138, 72 pp. [Available online at http://www.smhi.se/polopoly_fs/ 1.7843!/meteorologi_138.pdf.]

and —, 2011: Vind och storm i Sverige 1901-2010 (in Swedish). Swedish Meteorological and Hydrological Institute Rep. Faktablad 51, 4 pp. [Available online at http://www.smhi. se/polopoly_fs/1.16896!/webbFaktablad_51.pdf.]

Wilks, D. S., 2006a: On "field significance" and the false discovery rate. J. Appl. Meteor. Climatol., 45, 1181-1189, doi:10.1175/JAM2404.1. 2006b: Statistical Methods in the Atmospheric Sciences. 2nd ed. International Geophysics Series, Vol. 91, Academic Press, 627 pp.

Xu, M., C. P. Chang, C. Fu, Y. Qi, A. Robock, D. Robinson, and H. Zhang, 2006: Steady decline of East Asian monsoon winds, 1969-2000: Evidence from direct ground measurements of wind speed. J. Geophys. Res., 111, D24111, doi:10.1029/ 2006JD007337.

Yin, J., A. Wood, and B. Nijssen, 2009: 3TIER Inc. response to "Wind speed trends over the contiguous USA" by Sara Pryor and coauthors, to appear in J. Geophysical Research in August. [Available online at http://www.grainnet.com/pdf/ 3TIER.pdf.]

Young, I. R., S. Zieger, and A. V. Babanin, 2011: Global trends in wind speed and wave height. Science, 332, 451-455, doi:10.1126/ science.1197219. 